\title{
Cholesterol biosensing with a polydopamine-modified nanostructured platinum electrode prepared by oblique angle physical vacuum deposition
}

\author{
M. Martín ${ }^{1}$, P. Salazar ${ }^{2, *}$, R. Álvarez ${ }^{2}$, A. Palmero ${ }^{2}$, C. López-Santos ${ }^{2}$, J.L. González- \\ Mora $^{1}$ and Agustín R. González-Elipe ${ }^{2, \dagger}$
}

\begin{abstract}
${ }^{1}$ Neurochemistry and Neuroimaging Group, (Laboratory of Sensors, Biosensors and Materials) Faculty of Medical Sciences, University of La Laguna, Campus de Ofra s/n, 38071 La Laguna, Tenerife (Spain)

${ }^{2}$ Laboratory of Nanotechnology on Surfaces, Institute of Materials Science of Seville (CSIC-Univ. Sevilla), Calle Américo Vespucio 49, 41092, Sevilla (Spain)

Corresponding authors: "psalazar@icmse.csic.es, ${ }^{\dagger}$ arge@icmse.csic.es
\end{abstract}

\section{Abstract}

This paper reports a novel cholesterol biosensor based on nanostructured platinum $(\mathrm{Pt})$ thin films prepared by Magnetron Sputtering (MS) in an oblique angle (OAD) configuration. Pt thin films were deposited onto a gold screen-printed electrode and characterized using Rutherford Back Scattering (RBS), Scanning Electron Microscopy (SEM), X-ray Diffraction (XRD), Cyclic Voltammetry (CV), X-ray Photo-electron Spectroscopy (XPS), Atomic Force Microscopy (AFM) and wetting analysis. Our results confirmed that the film is highly porous and formed by tilted nanocolumns, with an inclination of around $40^{\circ}$ and a total thickness of $280 \mathrm{~nm}$. XRD and CV analysis confirmed the polycrystalline nature of the Pt thin film. Cholesterol oxidase (ChOx) was covalently immobilized using a bioinspired polymer, polydopamine (PDA), via Schiff base formation and Michael-type addition. After being immobilized, ChOx displayed an apparent activation energy of $34.09 \mathrm{~kJ} \mathrm{~mol}^{-1}$ and a Michaelis constant $\left(\mathrm{K}_{\mathrm{M}}\right)$ equal to $3.65 \mathrm{mM}$, confirming the high affinity between $\mathrm{ChOx}$ and cholesterol and the excellent ability of the PDA film for immobilizing biological material without degradation. Under optimized working conditions our biosensor presented a sensitivity of $14.3 \mathrm{~mA} \mathrm{M} \mathrm{cm}^{-1}$ $\left(\mathrm{R}^{2}: 0.999\right)$ with a linear range up to $0.5 \mathrm{mM}$ and a limit of detection of $10.5 \mu \mathrm{M}(\mathrm{S} / \mathrm{N}=$ 
$\mathrm{Au}-\mathrm{SPE} / \mathrm{Pt}$

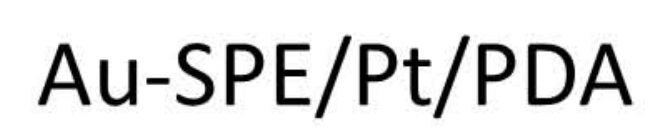

Au-SPE/Pt/PDA-ChOx
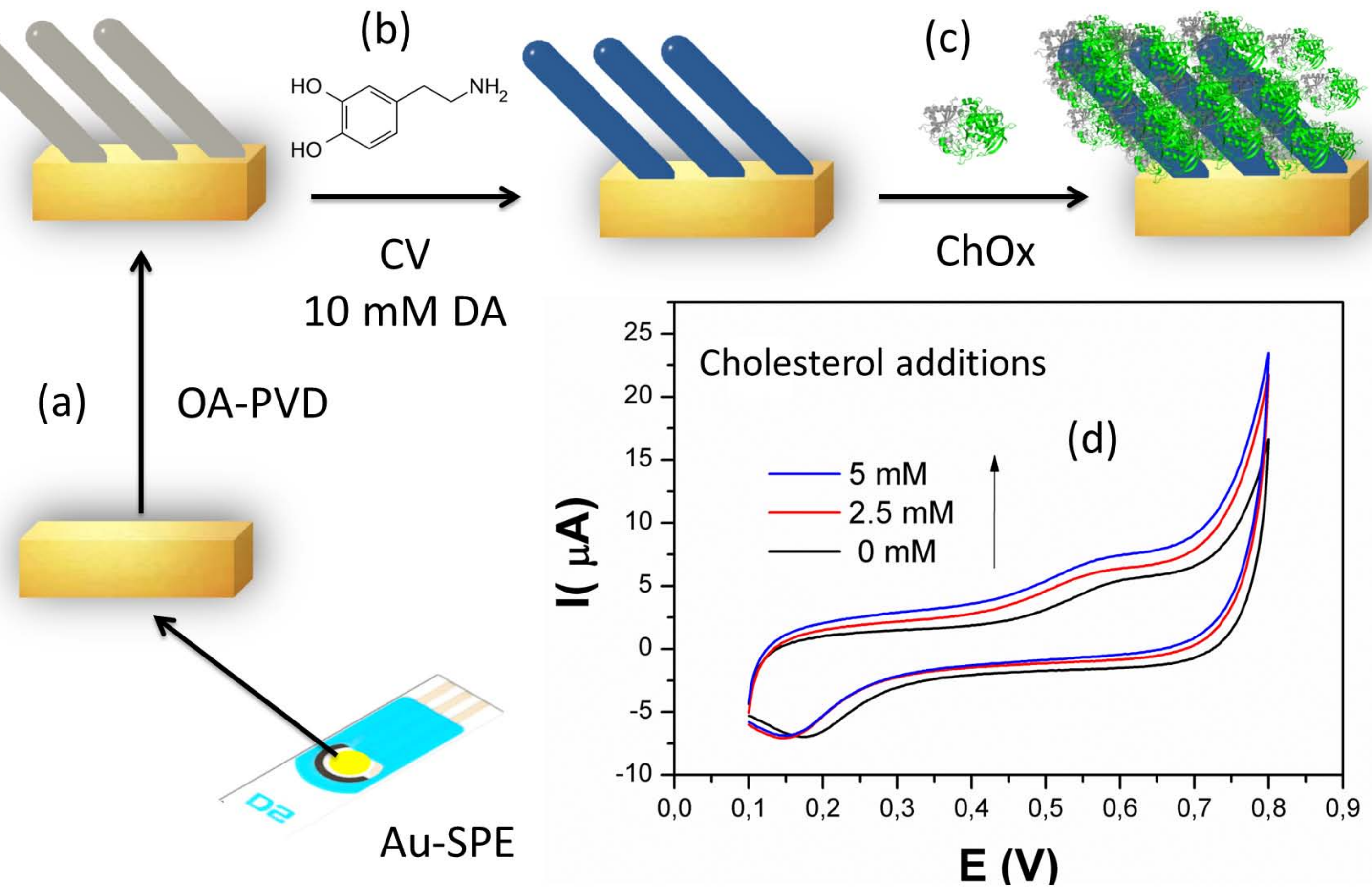
3). Furthermore the biosensor exhibits a fast response $(<8 s)$, good anti-interference properties and high stability after relatively long-term storage (2 months).

Keywords: Platinum, magnetron sputtering, oblique angle deposition, polydopamine, cholesterol, GLAD

\section{Introduction}

Present days are witnessing a growing demand of new sensor devices for analytical, health, agro-alimentary, pharmaceutical, defense and environmental applications. According to the International Union of Pure and Applied Chemistry (IUPAC) a biosensor is "a self-contained integrated device, which is capable of providing specific semi-quantitative or quantitative analytical information using a biological recognition element which is retained in direct spatial contact with a transduction element" [1]. Biosensors may replace or complement classical analytical methods (e.g. chromatography, capillary electrophoresis and mass spectrometry) simplifying or eliminating sample preparation steps and making field-testing easier and faster with a significant decrease in cost per analysis [2]. In particular, electrochemical biosensors are very attractive because of their low dimensions, high sensitivity and selectivity, low cost, real-time output, simplicity of starting materials or the possibility to develop userfriendly and ready-to-use devices [3, 4].

First-generation biosensors, based on the detection of an electroactive metabolites (e.g., $\mathrm{H}_{2} \mathrm{O}_{2}$ generated through an enzymatic reaction), are still preferred due to its easy and practical implementation [5]. Platinum $(\mathrm{Pt})$, thanks to its outstanding electrocatalytic properties, is the most common material for electrochemical detection of $\mathrm{H}_{2} \mathrm{O}_{2}$ [3-8]. This feature, together with the availability of commercial Pt electrodes in different configurations, alloy compositions and dimensions, make this material very attractive 
for biosensor applications. However, classical commercial Pt electrodes present polished and flat surfaces with a low surface to volume ratio that limit sensitivity and provide a great freedom of orientation to biomolecules anchored onto their surface (i.e., non-oriented immobilization). Random distribution and poor orientation of biomolecules may induce conformational changes (especially in the active/binding site) and biomolecule denaturation, as well as constrain the accessibility of the substrate to the active/binding sites $[9,10]$. These deleterious effects can be avoided using nanostructured porous layers with higher surface/volume ratios which, providing more effective surface sites for the immobilization of biomolecules with the desired orientation and conformation, present higher biological activity and enhance the sensing response capacity [10-13].

In the present work we combine both a new nanostructured $\mathrm{Pt}$ electrode and polydopamine (PDA), a bioinspired material, to develop a cholesterol biosensor. This combination ensures the correct immobilization of the biological recognition element (cholesterol oxidase) and preserves its electrocatalytic activity. Magnetron Sputtering (MS) has been selected to fabricate the Pt electrode [14]. This physical vapour deposition technique is typically used for the fabrication of compact films, a feature that restricts the expected functionality with regard to biomolecules. An alternative to conventional MS consists of using an oblique angle deposition configuration (MSOAD) where the substrate is placed at an oblique angle with respect to the target [1422]. This deposition geometry leads to the formation columnar and highly porous microstructure with mesopores extending from the surface of the film up to the interface with the substrate $[18,21]$.

PDA coatings have attracted considerable interests in the recent years because they can be applied in a simple and fast way to modify surfaces. This bioinspired polymer has 
been usefully applied for biomedical applications, remediation, biomineralization, drug delivery and hyperthermia, as well as for sensor and biosensor manufacturing [23, 24]. From a biosensor perspective an interesting feature of PDA is the possibility to covalently graft onto its residual quinone groups other nitrogen and thiol containing molecules through either Schiff base or Michael-type additions [23-27]. This possibility, together with a high reactivity and the possibility to cover an almost unlimited number of materials offer many unexplored opportunities for biosensor assemblies [23-32]. In fact, PDA provides a suitable microenvironment for immobilizing a high density of oriented biomolecules with their catalytic and biorecognition activity intact [23, 25, 33-37].

In the present work we prove that these concepts can be used for the development of a cholesterol biosensor consisting of a Pt porous electrode fabricated by MS-OAD, a PDA layer and a specific enzyme. The high performance of our biosensor, its good analytical response and interference properties and the retention of the enzymatic activity for a long time support the use of the developed complex electrodes as robust and reliable biosensors.

\section{Materials and Methods}

\subsection{Reagents, materials and solutions}

Cholesterol oxidase (ChOx) (C8868, from microorganism), dopamine (DA), cholesterol, Triton X-100 and all other chemicals were obtained from Sigma. The target for MS was supplied by SMP and consisted of a 1 inch diameter disk of high purity (99.99\%) platinum. Gold screen-printed electrodes (Au-SPE) (AT220, Dropsens) consisting of a 4-mm diameter gold working electrode, a gold counter electrode and a Ag pseudo-reference electrode were employed as electrochemical transducers. 
Phosphate buffer solutions (0.1 M, pH 7.4) were prepared in doubly distilled (DI) water (18.2 $\mathrm{M} \Omega \mathrm{cm}$, Millipore-Q). ChOx was dissolved $\left(1 \mathrm{mg} \mathrm{mL}^{-1}\right)$ in $50 \mathrm{mM}$ PBS with 0.1 $\mathrm{M} \mathrm{NaCl}$. PDA monomer solutions $(10 \mathrm{mM})$ were prepared in a PBS solution ( $\mathrm{pH} 7.4)$ before use. Since cholesterol does not dissolve well in standard buffer solutions, a nonionic surfactant (Triton X-100) was used [38-40]. Cholesterol stock solutions (5 and 10 $\mathrm{mM}$ ) were prepared in PBS incorporating 10\% (v/v) Triton X-100 which were slowly heated until $60{ }^{\circ} \mathrm{C}$ during $30 \mathrm{~min}$. The solutions were stored in a refrigerator and remained stable for 1 month (until a slight turbidity was observed). Electrochemical tests were carried out in $0.1 \mathrm{M}$ PBS with $1 \%(\mathrm{v} / \mathrm{v} /)$ Triton X-100 (PBST) [38]. The spectrophotometric kit for cholesterol determination was supplied by Linear Chemical SL.

\subsection{Preparation and characterization of the nanostructured platinum film}

\section{electrodes}

Nanostructured platinum thin films were deposited onto gold screen-printed (Au-SPE) substrates using the MS-OAD technique in a cylindrical vacuum reactor pumped down to a base pressure lower than $5 \times 10^{-4} \mathrm{~Pa}$ that was equipped with a magnetron sputtering target device (A310-XP, by AJA International). This base pressure was achieved by a combination of turbomolecular and rotary pumps. The gas used for the deposition was Ar (purity $99.995 \%$ ) and the working pressure was adjusted with a throttling valve placed between the chamber and the turbo pump at $0.4 \mathrm{~Pa}$. The electrodes were placed $70 \mathrm{~mm}$ apart from the target. Preparations were carried out using a unipolar power DC supply at a constant electromagnetic power of $40 \mathrm{~W}$. Deposition of platinum was performed at oblique angle by tilting the surface of the electrodes $85^{\circ}$ relative to the target [21]. A mask was placed over the electrodes to cover only the 4-mm diameter gold working layer (Au-SPE/Pt). 
Field emission scanning electron micrographs were obtained using a HITACHI S 4800 microscope for doped silicon supported films conveniently diced for cross section observation. Raman and FTIR spectra were taken with a HORIBA HR-800-UV microscope and a JASCO FT/IR-6200 spectrophotometer set in the "Attenuated Total Reflection" (ATR) mode, respectively. Wetting measurements were carried out according to the Young method measuring the contact angle of small water droplets (3 $\mu \mathrm{L}$ ) with a Contact Angle System OCA20 (DataPhysics). Topographic images of the surface were taken at the scale of $1 \mu \mathrm{mx} 1 \mu \mathrm{m}$ with a Nanotec AFM microscope and Dulcinea electronics, working in tapping mode and using high frequency levers. Data were processed with the WSxM software [41]. X-ray photo-electron spectroscopy (XPS) was carried out in a Phoibos-100 spectrometer, working in the pass energy constant mode, with $\mathrm{Mg} \mathrm{K} \alpha$ as excitation source. The binding energy scale was referenced at $284.5 \mathrm{eV}$ for the $\mathrm{C} 1 \mathrm{~s}$ peak of some slight contamination of carbon present on the electrode surface. X-ray diffraction spectra, obtained in a grazing angle configuration, were acquired using a Panalytical X'PERT PRO diffractometer. Rutherford back scattering, RBS, spectra were obtained in a tandem accelerator (CNA, Sevilla, Spain) with a beam of alpha particles with energy and intensity of ca. $2.1 \mathrm{MeV}$ and $1.7 \mathrm{nA}$ respectively, and ca. $1 \mathrm{~mm}$ diameter. RBS spectra were analyzed with the SIMRA6.0 program [42].

To evaluate the quality and the effective electrochemical area of the Pt thin film, cyclic voltammetry (CV) experiments were carried out with a DRP- $\mu$ STAT400 BiPotentiostat/Galvanostat, while data were acquired with the Dropview 8400 software (DropSens) in a $10 \mathrm{~mL}$ glass cell at room temperature. Therefore, a Pt-modified electrode was used as working electrode and a commercial $\mathrm{Ag} / \mathrm{AgCl}(3 \mathrm{M} \mathrm{KCl})$ and a Platinum (Pt) wire as reference and counter electrodes, respectively. 


\subsection{Biosensor fabrication and characterization}

PDA was directly electrodeposited using CV. To this end, a drop ( $80 \mu \mathrm{L})$ of $10 \mathrm{mM}$ DA was deposited onto both the working Ag pseudo-reference and counter electrodes, and cycled between -0.2 and $0.6 \mathrm{~V}$ at a scan rate of $0.1 \mathrm{~V} \mathrm{~s}^{-1}$ (default 20 cycles). Then, electrodes were washed several times with DI water to remove non-polymerized DA and subsequently dried under a $\mathrm{N}_{2}$ atmosphere. Enzymatic immobilization was done by casting the working electrode with $20 \mu \mathrm{L}$ of ChOx solution $\left(1 \mathrm{mg} \mathrm{mL}^{-1}\right)$ followed by its storage overnight in a wet atmosphere at $4{ }^{\circ} \mathrm{C}$. Finally, biosensors were washed several times with DI water to remove then non-immobilized enzyme, dried newly with $\mathrm{N}_{2}$ and stored at $4{ }^{\circ} \mathrm{C}$.

Biosensor electrochemical characterizations $(\mathrm{CV}$, chronoamperometry, constant potential amperometry) were carried using a full electrochemical cell configured on the Au-SPE. It consisted of a 4-mm diameter working electrode (Au-SPE/Pt/PDA-ChOx), a gold counter electrode and an Ag pseudo-reference electrode.

\section{Results and discussion}

Scheme 1 displays a schematic representation of the structure and concepts applied for the construction of the final cholesterol biosensor. The procedure encompasses the following steps: (a) deposition of the nanoporous Pt thin layer onto the Au-SPE, (b) PDA electrodeposition, (c) enzymatic immobilization and (d) biosensor response. A more detailed description of the procedure is reported in Section 2, materials and methods.

\section{MS-OAD thin film characterization}


The physicochemical properties and performance of the nanostructured Pt layers were determined using the techniques mentioned in the section 2.2. Figure 1 shows the topview (Fig. 1a, b) and cross-section (Fig. 1c) images of the Pt nanostructured layer prepared on a silicon substrate. The former reveals the porous nature of the Pt layer with a surface formed by separated and well-defined domains. Meanwhile, the latter shows a microstructure formed by $40^{\circ}$ tilted nanocolumns and a total thickness of ca. $280 \mathrm{~nm}$. This porous and nanostructured configuration of these OAD layers has been attributed to shadowing effects during the film growth [39]. Porosity of the Pt thin film was estimated from the mass thickness determined by RBS (see material supporting, Fig. S1) and its actual thickness determined from the FE-SEM cross-section image $[16,17]$. This comparative assessment yields a void space ratio of approximately $45 \%$ of the $\mathrm{Pt}$ thin film volume.

XRD analysis confirmed the deposition of a metallic and polycrystalline Pt thin film deposited on doped silicon (100) wafer. The diffractogram (in Fig. 2a) shows characteristic diffraction lines at ca. 39.78, 41.16, 67.47, 81.26 and 85.82 degrees that can be assigned to $\operatorname{Pt}(111), \operatorname{Pt}(200), \operatorname{Pt}(220), \operatorname{Pt}(311)$ and $\operatorname{Pt}(222)$ diffraction peaks [43]. A crystallite average size of ca. $22 \mathrm{~nm}$ was calculated with the Debye-Scherer equation using the full-width at half maximum (FWHM) value of the (111) XRD peak. Figure 2b displays the characteristic CVs in sulfuric media for Au-SPE/Pt electrodes with a porous and a compact configuration. They are characterized by two well-defined pairs of redox peaks, a first one (at ca. $-0.1 \mathrm{~V}$ ) related to the adsorption/desorption of hydrogen and a second one attributed to the formation of oxide/hydroxide species (ca. $+0.6 \mathrm{~V})$. The presence of a broad peak in the adsorption/desorption region confirmed the polycrystalline nature of the film $[44,45]$. From the intensity of the CV curves it was possible to confirm an enhancement in the exchange of charge at the porous film. 
Moreover, from the integrated area of the anodic peak at ca. $-0.1 \mathrm{~V}$, we calculated the electrochemical surface area (ESA) and the roughness factor (RF) of the Pt film electrode that were estimated according to:

$$
\begin{gathered}
E S A=Q / Q^{*} \text { (Eq. 1) } \\
R F=E S A / G S A \text { (Eq. 2) }
\end{gathered}
$$

where $\mathrm{Q}$ is the integrated charge of the anodic peak, $\mathrm{Q}^{*}$ is the standard value of $210 \mu \mathrm{C}$ $\mathrm{cm}^{-2}$ corresponding to a single hydrogen layer $\left(1.3 \times 10^{15}\right.$ atom $\left.\mathrm{cm}^{-2}\right)$ adsorbed onto a polycrystalline Pt electrode, and GSA is the geometrical area of the electrode [46, 47]. For the porous layer and a total charge of $253 \mu \mathrm{C}$, the determined ESA was $1.25 \mathrm{~cm}^{2}$, one order of magnitude higher than the GSA $\left(0.13 \mathrm{~cm}^{2}\right)$ and expected values for a compact Pt layer. The RF value determined with Eq. 2 was 9.2. In contrast, CV for the compact configuration displayed an ESA and RF values of ca. $0.13 \mathrm{~cm}^{2}$ and 1 respectively, and confirmed the advantages of working under the OAD approach.

The chemical oxidation state of the electrodeposited Pt porous thin film was determined by XPS. Figure 3a shows a general photoelectron spectrum recorded for the $\mathrm{Au}-\mathrm{SPE} / \mathrm{Pt}$ electrode which is very similar to spectra previously reported for other Pt electrodes [43]. The oxygen peak $(\mathrm{O} 1 \mathrm{~s})$ in this spectrum may be related with the formation of oxide species at the surface, while the carbon peak $(\mathrm{C} 1 \mathrm{~s})$ must be attributed to adventitious carbon. As shown in Figure 3b, the Pt 4f spectrum depicts two bands at binding energy values of 73.5 y $77.3 \mathrm{eV}$ and the intensity ratio typical of the $\mathrm{Pt}^{4} \mathrm{f}_{7 / 2}$ and $\mathrm{Pt} 4 \mathrm{f}_{5 / 2}$ components. These values are very close to the binding energies found for PtO $\left(\mathrm{Pt}^{2+}\right)$ and $\mathrm{PtO}_{2}\left(\mathrm{Pt}^{4+}\right)$, thus confirming the formation of an oxide layer on the surface of the electrode [48-50].

\subsection{Polydopamine-modified Pt porous thin film characterization}


Electropolymerization of Dopamine has been selected as a method to modify the Pt thin films. This procedure exhibits higher deposition rates and more efficient results in terms of dopamine recovery [51] than the more conventional self-polymerization [23, 24]. In addition, it is not time-consuming and leads to the complete coverage of the surface of the Pt electrode with a reactive polymeric layer quite well-suited for the covalent immobilization of ChOx. Figure 4a shows a cyclic voltammogram (CV) with a pair of peaks at $0.25 / 0.05 \mathrm{~V}$ that are typical for the electropolymerization of PDA. The anodic peak at $0.25 \mathrm{~V}$ is responsible for DA oxidation to ortho-dopaminoquinone and the cathodic peak at $0.05 \mathrm{~V}$ is related to ortho-dopaminoquinone reduction to DA [51]. In successive scans, the peak currents decrease cycle-by-cycle suggesting that a compact and insulating PDA film is progressively growing in thickness onto the electrode surface [52]. Figure 4b shows the CV for Au-SPE and Au-SPE/Pt electrodes, using the ferro/ferricyanide pair as redox probe. The suppression of the redox activity of this redox probe $[51,52]$ confirms the correct electrodeposition of PDA on the electrode surfaces.

Figure 5a shows the ATR-FTIR spectra of the Au-SPE/Pt and Au-SPE/Pt/PDA electrodes. The PDA-modified electrode depicts broad peaks at ca. $3300 \mathrm{~cm}^{-1}$ and $2900 \mathrm{~cm}^{-1}[25-27,53]$ that can be assigned to $v(\mathrm{~N}-\mathrm{H})$ and $v(\mathrm{O}-\mathrm{H})$ stretching modes (due to the presence of amino and hydroxyl groups) and to aliphatic $v(\mathrm{C}-\mathrm{H})$ stretching modes, respectively. The peak at $1720 \mathrm{~cm}^{-1}$ is assigned to $v(\mathrm{C}=\mathrm{O})$ groups, indicating the presence of quinone groups in the polymeric film [25-27]. Meanwhile, the peak at ca. $1450 \mathrm{~cm}^{-1}$, assigned either to the $v($ ring- $(\mathrm{C}=\mathrm{C}))$ or/and to $v($ ring- $(\mathrm{C}=\mathrm{N}))$ stretching modes, together with the peak at ca. $1390 \mathrm{~cm}^{-1}$, confirm the presence of aromatic amine species in the deposited film [25-27]. Raman spectra (Fig. 6b) for Au-SPE/Pt electrodes present three overlapping peaks in the range $1000-1900 \mathrm{~cm}^{-1}$. The two latter, at 1400 
and $1600 \mathrm{~cm}^{-1}$, can be associated with the stretching and deformation of catechol groups in the polymeric film $[25-27,54]$ and confirm the succefuly electrodeposition of PDA onto the Pt surface. Interestingly, the peak at $1100 \mathrm{~cm}^{-1}$ has not been reported in previous works dealing with PDA biosensing applications and its development in this case must be associated with the use of slight alkaline conditions during the electrodeposition of PDA $[18,19,46]$. We relate the appearance of this peak in PDA, otherwise typical of DA [55], to the entrapping/adsorption of the monomer in/on the polymeric film during the rapid electropolymerization process and its retention after washing [56].

Additional characterization of the Au-SPE/Pt and Au-SPE/Pt/PDA surface morphologies has been performed by AFM. Since the Au-SPE/Pt and Au-SPE/Pt/PDA surfaces present similar grain-like topographies (see figure $\mathbf{S 2}$ in the supporting information) and their roughness expressed as root mean square (RMS) values only increases from 7.5 to $13.1 \mathrm{~nm}$ after PDA deposition, it is possible to conclude that the PDA coating covers conformably the Pt surface. It is noteworthy that, within the expected discrepancies between the two techniques, the determined Pt AFM surface roughness (i.e., RMS value) is in good agreement with the roughness factor obtained by electrochemical analysis (see above).

Since the surface tensions of metallic and polymeric materials are very different [57], another surface property that may confirm the complete covering of the Pt electrode with the PDA film is a change in wettability. This property depends on several factors including the roughness and chemical functionalities of the surface [58]. WCAs on the $\mathrm{Au}-\mathrm{SPE} / \mathrm{Pt}$ and Au-SPE/Pt/PDA surfaces (see Figure S3 in the supporting information for the shape of the droplets) present values of $100^{\circ}$ and $76^{\circ}$ respectively. Clean flat platinum surfaces are typically hydrophilic (i.e. WCA smaller that 90 ${ }^{\circ}$ [59], while a 
hydrophobic behavior (WCA higher than $90^{\circ}$ ) is only achieved after chemical surface modification of microstructured platinum samples [60]. Therefore, the hydrophobic behavior found for the MS-OAD Pt film must be attributed to its rough character and oxidized surface state after the electrochemical activation. However, most interesting for the present investigation is that the WCA decreases to $76^{\circ}$ when this oxidized $\mathrm{Pt}$ electrode is coated with the PDA film. Since the RMS values are similar for the two electrodes, this improved wettability must be attributed to the formation of a new liquid-surface interface with a higher surface tension due to the different chemical nature of the latter after PDA deposition.

\subsection{Cholesterol oxidase-modified Au-SPE/Pt electrodes characterization}

In order to demonstrate the biosensing possibilities of the PDA-modified Pt electrodes, cholesterol oxidase (ChOx) was immobilized on their surface. Cyclic voltammogrametry $(\mathrm{CV})$ and chronoamperometry (see in supplementary materials, Fig. S4) were used to characterize the electrochemical behavior of the cholesterol biosensor (Au-SPE/Pt/PDA-ChOx). After the addition of cholesterol, the CV of the AuSPE/Pt/PDA-ChOx biosensor showed a noticeable increase in current (Fig. 6a), starting at about $+0.20 \mathrm{~V}$ and depicting a clear anodic peak shoulder at around $+0.55 \mathrm{~V}$. This behavior was reproducible during successive additions and can be attributed to the oxidation of the $\mathrm{H}_{2} \mathrm{O}_{2}$ generated during the enzymatic reaction. The effect of the scan rate on the anodic peak was studied cycling the Au-SPE/Pt//PDA-ChOx biosensor in 2.5 $\mathrm{mM}$ cholesterol solution in the range 0.01-0.35 $\mathrm{V} \mathrm{s}^{-1}$ (Fig. 6b). The obtained linear dependence between the peak current and the square root of scan rate (Fig. 6c) indicates that the diffusion of cholesterol, rather than a surface-bound process, is the limiting step of the reaction rate. In turn, these results suggest that a rapid electron transfer process occurs at the surface of the electrode, a situation that is ideal for analytical applications. 


\subsubsection{Applied potential, $\mathrm{pH}$ and temperature effects}

The effect of the applied potential, $\mathrm{pH}$ and temperature on the amperometric response of the $\mathrm{Au}-\mathrm{SPE} / \mathrm{Pt}-\mathrm{ChOx}$ biosensor against $1 \mathrm{mM}$ cholesterol was conveniently evaluated to determine the application ranges of the developed cholesterol biosensor electrode. The choice of the proper potential applied at the working electrode is critical to increase the sensitivity towards $\mathrm{H}_{2} \mathrm{O}_{2}$ and, therefore, to lower the detection limit, improving the analytical performance of the system. Traditionally, in most biosensors based on $\mathrm{Pt}$ electrodes, detection of $\mathrm{H}_{2} \mathrm{O}_{2}$ is carried out at relatively high potentials (ca. $+0.7 \mathrm{~V}$ ), conditions that are prompt to interferences with other electroactive stuffs in the medium $[4,61]$. Evaluation of the Au-SPE/Pt-ChOx biosensor in the range 0 to $+0.7 \mathrm{~V}$ (see Fig. S5a in the supporting information) showed a clear enhancement in sensitivity at $+0.2 \mathrm{~V}$, a maximum at $+0.4 \mathrm{~V}$ and no additional improvement at higher potentials. This behavior, agreeing with both the $\mathrm{CV}$ data discussed above and the good electrocatalytic activity of nanostructured Pt electrodes previously reported by other authors [61, 62], strongly supports the use of these electrodes as a robust device for the detection of cholesterol.

The effect of $\mathrm{pH}$ on the amperometric response of the biosensor was checked in the $\mathrm{pH}$ range 4.0 to 10.0 (see Figure S5b in the supporting information). The biosensor current exhibited an almost bell-shaped behavior, with a maximum response at an onset $\mathrm{pH}$ of 7.4 that extends up to $\mathrm{pH} 9$, confirming the excellent stabilization of the enzyme on the surface of the PDA film. Based on these results, $+0.4 \mathrm{~V}$ and $\mathrm{pH} 7.4$ were selected for further analysis.

The effect of temperature on the Au-SPE/Pt-ChOx biosensor response was evaluated from 15 to $60{ }^{\circ} \mathrm{C}$. As shown in Figure 7a, the response current increased with 
temperature up to a maximum value at $45^{\circ} \mathrm{C}$ due to an enhancement in the activity of the immobilized ChOx. Then, the enzyme activity slightly decreased (ca. 10\%) at higher temperatures $\left(<55^{\circ} \mathrm{C}\right)$ due to the deactivation of $\mathrm{ChOx}$. The apparent activation energy, calculated according to the Arrhenius theory [27], had a value of $34.09 \mathrm{~kJ} \mathrm{~mol}^{-1}$ (c.f., Figure $7 \mathbf{b}$ ), i.e., it was lower than the values of 42.6 and $71.1 \mathrm{~kJ} \mathrm{~mol}^{-1}$ reported by previous authors $[38,40]$. This result further confirms that ChOx activity is properly retained on the surface of the PDA-modified Pt electrode.

\subsubsection{Biosensor response under optimized conditions}

After optimizing the main experimental variables, the biosensor response was newly revised. For convenience, all measurements were carried out at ambient temperature. Figure 8a shows the amperometric response of the Au-SPE/Pt/PDA-ChOx biosensor (under stirring conditions) for successive cholesterol additions. Each time, the biosensor presented a fast response after a short stabilization time of ca. $8 \mathrm{~s}$. This low value confirms that this hybrid configuration does not present significant diffusional problems and demonstrate that the very thin nature of the PDA film and the excellent electrocatalytic properties of the nanostructured Pt layer are quite adequate for their use as biosensor assembly. As shown in Figure $\mathbf{8 b}$, the calibration curve presented a Michaelis-Menten (MM) behavior. Enzyme kinetics parameters obtained using the Hill modified MM equations yielded values of $\mathrm{K}_{\mathrm{M}}=3.65 \mathrm{mM}, \mathrm{V}_{\max }=6.93 \mu \mathrm{A}$ and Hill parameter $(\mathrm{h})=0.99$. The $\mathrm{h}$ value obtained indicates that the biosensor responds according to a MM kinetic ( $\mathrm{h}=1$, for $\mathrm{MM}$ mechanism). $\mathrm{K}_{\mathrm{M}}$ determines the affinity of an enzyme for a specific substrate, smaller values of this magnitude signifying a higher affinity [25-27]. Therefore, the low $\mathrm{K}_{\mathrm{M}}$ value obtained for the developed biosensor, in line with previous values reported in literature for other systems [38, 63-66], confirms 
that $\mathrm{ChOx}$ is well immobilized on the PDA film where it retains its enzyme structure with very little conformational changes.

The biosensor presented a linear response with cholesterol concentration up to a value of $0.5 \mathrm{mM}$, with a sensitivity in this range of $14.3 \mathrm{~mA} \mathrm{M} \mathrm{cm}^{-1}\left(\mathrm{R}^{2}=0.999\right)$ that is comparable or even superior than that of other complex biosensor designs [40, 65, 67-73] (Table 1). The calculated limits of detection (LOD) $(\mathrm{S} / \mathrm{N}=3)$ and quantification (LOQ) $(\mathrm{S} / \mathrm{N}=10)$ were 10.5 and $35.3 \mu \mathrm{M}$, respectively, in line with other similar nanostructured biosensors (Table 1). The reproducibility and repeatability of the $\mathrm{Au}-\mathrm{SPE} / \mathrm{Pt} / \mathrm{PDA}-\mathrm{ChOx}$ biosensor activity was evaluated by measuring the slope of calibration plots for cholesterol in the $0-500 \mathrm{mM}$ concentration range. Relative standard deviation (RSD) values were 3.2 and $7.4 \%$ as determined for three calibrations plots successively obtained with the same electrode or with three different biosensors prepared in the same manner, respectively.

The effect of common interfering substances in cholesterol determination such as ascorbic acid, glucose and lactate was also investigated. Interference tests were carried out with $5 \mathrm{mM}$ cholesterol (normal value in human blood), comparing the current changes in the presence of $0.1 \mathrm{mM} \mathrm{AA}$ and $5 \mathrm{mM}$ for glucose and lactate. As shown in Figure S6a, all tested interferences produce negligible effects onto the actual cholesterol signal, thus confirming the high selectivity of the developed biosensor for cholesterol detection.

In order to compare our biosensor against common methods used for cholesterol determination, different cholesterol solutions were prepared in PBST and measured with both electrochemical and spectrophotometric methods. Recoveries obtained for both methods (Table S1) were in the same range 96-103\% clearly sustaining a good 
accuracy and reliability of our biosensor. Short term biosensor stability was studied during ca. $1 \mathrm{~h}$ after adding $400 \mu \mathrm{M}$ cholesterol. Our results showed an excellent response and retained more than the $95 \%$ of the initial response after the addition (Figure S6b). The long term stability of the biosensor was proved after its storage in a refrigerator at $4{ }^{\circ} \mathrm{C}$ for 2 months. It is noticeable in these experiments that the biosensor depicted no significant losses of sensitivity after the first month and retained ca. $85 \%$ of the initial activity after 2 months (Figure S7), duplicating the stabilities of the majority of cholesterol biosensors displayed in Table 1. This feature confirmed that $\mathrm{ChOx}$ is firmly retained on the surface of the biosensor and effectively stabilized even after long time periods.

\section{Conclusions}

In this work we have developed a novel cholesterol biosensor based on a specifically designed porous platinum thin film electrodes. Control over the porosity and nanostructure of the Pt thin films used as electrodes was possible using an oblique angle configuration during their physical vapor deposition with the magnetron sputtering technique. Using this type of thin films we have prepared a complex biosensor electrode integrating the Pt film a polydopamine layer and cholesterol oxidase. This assembply presented and excellent biosensor response which, having a low $\mathrm{K}_{\mathrm{M}}$ value, high temporal stability, high sensitivity and excellent response time, confirm the ability of this hybrid structure as an excellent biosensing platform for cholesterol determination and further investigations.

\section{Acknowledgements}

The support by project RECUPERA 2020 from MINECO and the"Fondo social Europeo”, IPT-2012-0961-300000, MAT2013-40852-R are gratefully acknowledged. 
M. Martín acknowledges Dr. Morales grant (Fundación Canaria Doctor Manuel Morales, La Palma, Spain)

\section{References}

[1] D.R. Thévenot, K. Toth, R.A. Durst, G.S. Wilson, Electrochemical biosensors: recommended definitions and classification1, Biosensors and Bioelectronics, 16(2001) 121-31.

[2] C.S. Pundir, N. Chauhan, Acetylcholinesterase inhibition-based biosensors for pesticide determination: A review, Analytical Biochemistry, 429(2012) 19-31.

[3] J. Wang, Electrochemical Glucose Biosensors, Chemical Reviews, 108(2008) 81425.

[4] P. Salazar, M. Martín, R. O'Neill, P. Lorenzo-Luis, R. Roche, J. González-Mora, Prussian Blue and Analogues: Biosensing Applications in Health Care, Advanced Biomaterials and Biodevices, John Wiley \& Sons, Inc.2014, pp. 423-50.

[5] R.D. O’Neill, G. Rocchitta, C.P. McMahon, P.A. Serra, J.P. Lowry, Designing sensitive and selective polymer/enzyme composite biosensors for brain monitoring in vivo, TrAC Trends in Analytical Chemistry, 27(2008) 78-88.

[6] P. Salazar, M. Martín, R. Roche, R.D. O’Neill, J.L. González-Mora, Prussian Bluemodified microelectrodes for selective transduction in enzyme-based amperometric microbiosensors for in vivo neurochemical monitoring, Electrochimica Acta, 55(2010) 6476-84.

[7] P. Salazar, M. Martín, R.D. O’Neill, R. Roche, J.L. González-Mora, Biosensors Based On Prussian Blue Modified Carbon Fibers Electrodes for Monitoring Lactate in The Extracellular Space of Brain Tissue, Int J Electrochem Sci, 7(2012) 5910 - 26.

[8] P. Salazar, M. Martín, R.D. O’Neill, R. Roche, J.L. González-Mora, Surfactantpromoted Prussian Blue-modified carbon electrodes: Enhancement of electro-deposition step, stabilization, electrochemical properties and application to lactate microbiosensors for the neurosciences, Colloids and Surfaces B: Biointerfaces, 92(2012) 180-9.

[9] S.A. Ansari, Q. Husain, Potential applications of enzymes immobilized on/in nano materials: A review, Biotechnology Advances, 30(2012) 512-23.

[10] J.N. Talbert, J.M. Goddard, Enzymes on material surfaces, Colloids and Surfaces B: Biointerfaces, 93(2012) 8-19.

[11] P.R. Solanki, A. Kaushik, V.V. Agrawal, B.D. Malhotra, Nanostructured metal oxide-based biosensors, NPG Asia Mater, 3(2011) 17-24.

[12] A. Sassolas, L.J. Blum, B.D. Leca-Bouvier, Immobilization strategies to develop enzymatic biosensors, Biotechnology Advances, 30(2012) 489-511.

[13] C. Mateo, J.M. Palomo, G. Fernandez-Lorente, J.M. Guisan, R. FernandezLafuente, Improvement of enzyme activity, stability and selectivity via immobilization techniques, Enzyme and Microbial Technology, 40(2007) 1451-63.

[14] P. Salazar, F.J. Garcia-Garcia, F. Yubero, J. Gil-Rostra, A.R. González-Elipe, Characterization and application of a new $\mathrm{pH}$ sensor based on magnetron sputtered porous WO3 thin films deposited at oblique angles, Electrochimica Acta, 193(2016) 2431.

[15] G.-G. Lola, P.-B. Julián, R.S.-V. Juan, B. Angel, B. Ana, R.G.-E. Agustín, et al., Correlation lengths, porosity and water adsorption in TiO 2 thin films prepared by glancing angle deposition, Nanotechnology, 23(2012) 205701. 
[16] P. Salazar, V. Rico, A.R. González-Elipe, Nickel-copper bilayer nanoporous electrode prepared by physical vapor deposition at oblique angles for the non-enzymatic determination of glucose, Sensors and Actuators B: Chemical, 226(2016) 436-43.

[17] P. Salazar, V. Rico, R. Rodríguez-Amaro, J.P. Espinós, A.R. González-Elipe, New Copper wide range nanosensor electrode prepared by physical vapor deposition at oblique angles for the non-enzimatic determination of glucose, Electrochimica Acta, 169(2015) 195-201.

[18] A. Barranco, A. Borras, A.R. Gonzalez-Elipe, A. Palmero, Perspectives on oblique angle deposition of thin films: From fundamentals to devices, Progress in Materials Science, 76(2016) 59-153.

[19] M.M. Hawkeye, M.T. Taschuk, M.J. Brett, Introduction: Glancing Angle Deposition Technology, Glancing Angle Deposition of Thin Films, John Wiley \& Sons, Ltd2014, pp. 1-30.

[20] R. Alvarez, J.M. Garcia-Martin, M.C. Lopez-Santos, V. Rico, F.J. Ferrer, J. Cotrino, et al., On the Deposition Rates of Magnetron Sputtered Thin Films at Oblique Angles, Plasma Processes and Polymers, 11(2014) 571-6.

[21] R. Alvarez, J.M. García-Martín, M. Macías-Montero, L. Gonzalez-Garcia, J.C. González, V. Rico, et al., Growth regimes of porous gold thin films deposited by magnetron sputtering at oblique incidence: from compact to columnar microstructures, Nanotechnology, 24(2013) 045604.

[22] R. Alvarez, C. Lopez-Santos, J. Parra-Barranco, V. Rico, A. Barranco, J. Cotrino, et al., Nanocolumnar growth of thin films deposited at oblique angles: Beyond the tangent rule, Journal of Vacuum Science \& Technology B, 32(2014) 041802.

[23] C.-C. Ho, S.-J. Ding, Structure, Properties and Applications of Mussel-Inspired Polydopamine, Journal of Biomedical Nanotechnology, 10(2014) 3063-84.

[24] Y. Liu, K. Ai, L. Lu, Polydopamine and Its Derivative Materials: Synthesis and Promising Applications in Energy, Environmental, and Biomedical Fields, Chemical Reviews, 114(2014) 5057-115.

[25] M. Martín, A. González Orive, P. Lorenzo-Luis, A. Hernández Creus, J.L. González-Mora, P. Salazar, Quinone-Rich Poly(dopamine) Magnetic Nanoparticles for Biosensor Applications, ChemPhysChem, 15(2014) 3742-52.

[26] M. Martin, P. Salazar, R. Villalonga, S. Campuzano, J.M. Pingarron, J.L. Gonzalez-Mora, Preparation of core-shell Fe3O4@poly(dopamine) magnetic nanoparticles for biosensor construction, Journal of Materials Chemistry B, 2(2014) 739-46.

[27] M. Martin, P. Salazar, S. Campuzano, R. Villalonga, J.M. Pingarron, J.L. Gonzalez-Mora, Amperometric magnetobiosensors using poly(dopamine)-modified Fe3O4 magnetic nanoparticles for the detection of phenolic compounds, Analytical Methods, 7(2015) 8801-8.

[28] Y. Li, Y. Tan, W. Deng, Q. Xie, Y. Zhang, J. Chen, et al., Electropolymerization of catecholamines after laccase-catalyzed preoxidation to efficiently immobilize glucose oxidase for sensitive amperometric biosensing, Sensors and Actuators B: Chemical, 151(2010) 30-8.

[29] A. Gao, Y.-R. Wang, X.-W. He, X.-B. Yin, An Electrochemical Hydrogen Peroxide Biosensor Based on Polydopamine-Entrapped G-Quadruplex-Hemin DNAzyme, Chinese Journal of Analytical Chemistry, 40(2012) 1471-6.

[30] R. Luo, L. Tang, J. Wang, Y. Zhao, Q. Tu, Y. Weng, et al., Improved immobilization of biomolecules to quinone-rich polydopamine for efficient surface functionalization, Colloids and Surfaces B: Biointerfaces, 106(2013) 66-73. 
[31] H. Lee, S.M. Dellatore, W.M. Miller, P.B. Messersmith, Mussel-Inspired Surface Chemistry for Multifunctional Coatings, Science (New York, NY), 318(2007) 426-30.

[32] Y.J. Chuah, Y.T. Koh, K. Lim, N.V. Menon, Y. Wu, Y. Kang, Simple surface engineering of polydimethylsiloxane with polydopamine for stabilized mesenchymal stem cell adhesion and multipotency, Scientific Reports, 5(2015) 18162.

[33] P. Jolly, V. Tamboli, R.L. Harniman, P. Estrela, C.J. Allender, J.L. Bowen, Aptamer-MIP hybrid receptor for highly sensitive electrochemical detection of prostate specific antigen, Biosensors and Bioelectronics, 75(2016) 188-95.

[34] L. Ji, T. Yan, Y. Li, J. Gao, Q. Wang, L. Hu, et al., Preparation of Aupolydopamine functionalized carbon encapsulated $\mathrm{Fe} 3 \mathrm{O} 4$ magnetic nanocomposites and their application for ultrasensitive detection of carcino-embryonic antigen, Scientific Reports, 6(2016) 21017.

[35] C. Ruan, W. Shi, H. Jiang, Y. Sun, X. Liu, X. Zhang, et al., One-pot preparation of glucose biosensor based on polydopamine-graphene composite film modified enzyme electrode, Sensors and Actuators B: Chemical, 177(2013) 826-32.

[36] Y. Li, C. Qin, C. Chen, Y. Fu, M. Ma, Q. Xie, Highly sensitive phenolic biosensor based on magnetic polydopamine-laccase-Fe3O4 bionanocomposite, Sensors and Actuators B: Chemical, 168(2012) 46-53.

[37] D. Li, L. Luo, Z. Pang, L. Ding, Q. Wang, H. Ke, et al., Novel Phenolic Biosensor Based on a Magnetic Polydopamine-Laccase-Nickel Nanoparticle Loaded Carbon Nanofiber Composite, ACS Applied Materials \& Interfaces, 6(2014) 5144-51.

[38] X. Tan, M. Li, P. Cai, L. Luo, X. Zou, An amperometric cholesterol biosensor based on multiwalled carbon nanotubes and organically modified sol-gel/chitosan hybrid composite film, Analytical Biochemistry, 337(2005) 111-20.

[39] S. Brahim, D. Narinesingh, A. Guiseppi-Elie, Amperometric determination of cholesterol in serum using a biosensor of cholesterol oxidase contained within a polypyrrole-hydrogel membrane, Analytica Chimica Acta, 448(2001) 27-36.

[40] H. Wang, S. Mu, Bioelectrochemical characteristics of cholesterol oxidase immobilized in a polyaniline film, Sensors and Actuators B: Chemical, 56(1999) 22-30.

[41] I. Horcas, R. Fernández, J.M. Gómez-Rodríguez, J. Colchero, J. Gómez-Herrero, A.M. Baro, WSXM: A software for scanning probe microscopy and a tool for nanotechnology, Review of Scientific Instruments, 78(2007) 013705.

[42] M. Mayer, SIMNRA User's Guide, Tech Rep IPP 9/113, Max-Plan,k-Institut fur Plasmaphysik, Garching, Germany (1997).

[43] S. Du, Y. Lu, S.K. Malladi, Q. Xu, R. Steinberger-Wilckens, A simple approach for PtNi-MWCNT hybrid nanostructures as high performance electrocatalysts for the oxygen reduction reaction, Journal of Materials Chemistry A, 2(2014) 692-8.

[44] A. Tegou, S. Papadimitriou, E. Pavlidou, G. Kokkinidis, S. Sotiropoulos, Oxygen reduction at platinum- and gold-coated copper deposits on glassy carbon substrates, Journal of Electroanalytical Chemistry, 608(2007) 67-77.

[45] A. Papaderakis, N. Pliatsikas, C. Prochaska, K.M. Papazisi, S.P. Balomenou, D. Tsiplakides, et al., Ternary Pt-Ru-Ni catalytic layers for methanol electrooxidation prepared by electrodeposition and galvanic replacement, Frontiers in Chemistry, 2(2014).

[46] D. Chi Linh, P. Thy San, N. Ngoc Phong, T. Viet Quan, Properties of Pt/C nanoparticle catalysts synthesized by electroless deposition for proton exchange membrane fuel cell, Advances in Natural Sciences: Nanoscience and Nanotechnology, 4(2013) 035011. 
[47] H. Olivia, B.V. Sarada, K. Honda, A. Fujishima, Continuous glucose monitoring using enzyme-immobilized platinized diamond microfiber electrodes, Electrochimica Acta, 49(2004) 2069-76.

[48] J. Xu, X. Liu, Y. Chen, Y. Zhou, T. Lu, Y. Tang, Platinum-Cobalt alloy networks for methanol oxidation electrocatalysis, Journal of Materials Chemistry, 22(2012) 23659-67.

[49] H.S. Kibombo, C.-M. Wu, R. Peng, J. Baltrusaitis, R.T. Koodali, Investigation of the role of platinum oxide for the degradation of phenol under simulated solar irradiation, Applied Catalysis B: Environmental, 136-137(2013) 248-59.

[50] B. Ohtani, K. Iwai, S.-i. Nishimoto, S. Sato, Role of Platinum Deposits on Titanium(IV) Oxide Particles: Structural and Kinetic Analyses of Photocatalytic Reaction in Aqueous Alcohol and Amino Acid Solutions, The Journal of Physical Chemistry B, 101(1997) 3349-59.

[51] J.-1. Wang, B.-c. Li, Z.-j. Li, K.-f. Ren, L.-j. Jin, S.-m. Zhang, et al., Electropolymerization of dopamine for surface modification of complex-shaped cardiovascular stents, Biomaterials, 35(2014) 7679-89.

[52] B. Stöckle, D.Y.W. Ng, C. Meier, T. Paust, F. Bischoff, T. Diemant, et al., Precise Control of Polydopamine Film Formation by Electropolymerization, Macromolecular Symposia, 346(2014) 73-81.

[53] R.A. Zangmeister, T.A. Morris, M.J. Tarlov, Characterization of Polydopamine Thin Films Deposited at Short Times by Autoxidation of Dopamine, Langmuir, 29(2013) 8619-28.

[54] B. Fei, B. Qian, Z. Yang, R. Wang, W.C. Liu, C.L. Mak, et al., Coating carbon nanotubes by spontaneous oxidative polymerization of dopamine, Carbon, 46(2008) 1795-7.

[55] N.S. Lee, Y.Z. Hsieh, R.F. Paisley, M.D. Morris, Surface-enhanced Raman spectroscopy of the catecholamine neurotransmitters and related compounds, Analytical Chemistry, 60(1988) 442-6.

[56] D.R. Dreyer, D.J. Miller, B.D. Freeman, D.R. Paul, C.W. Bielawski, Elucidating the Structure of Poly(dopamine), Langmuir, 28(2012) 6428-35.

[57] Z. Ma, Z. Mao, C. Gao, Surface modification and property analysis of biomedical polymers used for tissue engineering, Colloids and Surfaces B: Biointerfaces, 60(2007) 137-57.

[58] G. Kumar, K.N. Prabhu, Review of non-reactive and reactive wetting of liquids on surfaces, Advances in Colloid and Interface Science, 133(2007) 61-89.

[59] K.W. Bewig, W.A. Zisman, The Wetting of Gold and Platinum by Water, The Journal of Physical Chemistry, 69(1965) 4238-42.

[60] Y. Furukawa, T. Hoshino, Y. Morizawa, Method for the preparation of hydrophilic/hydrophobic patterned surfaces with photoinitiated hydrosilylation, Journal of Applied Polymer Science, 112(2009) 910-6.

[61] G. Sanzo, I. Taurino, G.D. Micheli, S. Carrara, G. Favero, F. Mazzei, Highly sensitive electrodic materials based on Pt nanoflowers grown on Pt nanospheres for biosensor development, Nanotechnology (IEEE-NANO), 2015 IEEE 15th International Conference on2015, pp. 1501-4.

[62] G. Yin, L. Xing, X.-J. Ma, J. Wan, Non-enzymatic hydrogen peroxide sensor based on a nanoporous gold electrode modified with platinum nanoparticles, Chemical Papers, 68(2013) 435-41.

[63] C.S. Pundir, J. Narang, N. Chauhan, P. Sharma, R. Sharma, An amperometric cholesterol biosensor based on epoxy resin membrane bound cholesterol oxidase, Indian Journal of Medical Research, 136(2012) 633-40. 
[64] S. Singh, A. Chaubey, B.D. Malhotra, Amperometric cholesterol biosensor based on immobilized cholesterol esterase and cholesterol oxidase on conducting polypyrrole films, Analytica Chimica Acta, 502(2004) 229-34.

[65] A. Umar, M.M. Rahman, M. Vaseem, Y.-B. Hahn, Ultra-sensitive cholesterol biosensor based on low-temperature grown $\mathrm{ZnO}$ nanoparticles, Electrochemistry Communications, 11(2009) 118-21.

[66] M.B. Gholivand, M. Khodadadian, Amperometric cholesterol biosensor based on the direct electrochemistry of cholesterol oxidase and catalase on a graphene/ionic liquid-modified glassy carbon electrode, Biosensors and Bioelectronics, 53(2014) 4728.

[67] C. Dhand, S.K. Arya, M. Datta, B.D. Malhotra, Polyaniline-carbon nanotube composite film for cholesterol biosensor, Analytical Biochemistry, 383(2008) 194-9.

[68] N. Po-Chin, P.-Y. Chen, H. Kuo-Chuan, Fabricating an Amperometric Cholesterol Biosensor by a Covalent Linkage between Poly(3-thiopheneacetic acid) and Cholesterol Oxidase, Sensors, 9(2009) 1794.

[69] A. Safavi, F. Farjami, Electrodeposition of gold-platinum alloy nanoparticles on ionic liquid-chitosan composite film and its application in fabricating an amperometric cholesterol biosensor, Biosensors and Bioelectronics, 26(2011) 2547-52.

[70] Y.-C. Tsai, S.-Y. Chen, C.-A. Lee, Amperometric cholesterol biosensors based on carbon nanotube-chitosan-platinum-cholesterol oxidase nanobiocomposite, Sensors and Actuators B: Chemical, 135(2008) 96-101.

[71] Ö. Türkarslan, S.K. Kayahan, L. Toppare, A new amperometric cholesterol biosensor based on poly(3,4-ethylenedioxypyrrole), Sensors and Actuators B: Chemical, 136(2009) 484-8.

[72] J.C. Vidal, E. Garcia-Ruiz, J.R. Castillo, Strategies for the improvement of an amperometric cholesterol biosensor based on electropolymerization in flow systems: use of charge-transfer mediators and platinization of the electrode, Journal of Pharmaceutical and Biomedical Analysis, 24(2000) 51-63.

[73] H.B. Yildiz, D.O. Demirkol, S. Sayin, M. Yilmaz, O. Koysuren, M. Kamaci, New Amperometric Cholesterol Biosensors Using Poly(ethyleneoxide) Conducting Polymers, Journal of Macromolecular Science, Part A, 50(2013) 1075-84. 


\section{Figure and Tables Captions}

Scheme 1 Schematic illustration for the different stages (a-c) of the cholesterol biosensor construction. The $\mathrm{CV}$ diagrams in d) represent $\mathrm{CV}$ evolution at different cholesterol concentrations.

Fig. 1 FE-SEM view (a, b) and cross-section micrographs (c) of a Pt porous thin film deposited by MS-OAD on a flat silicon wafer.

Fig. 2 (a) X-ray diffractogram (XRD) obtained for a platinum-modified silicon wafer.

(b) Cyclic voltammogram (CV) recorded for porous and compact Au-SPE/Pt electrodes in $0.5 \mathrm{M} \mathrm{H}_{2} \mathrm{SO}_{4}$ (scan rate: $0.1 \mathrm{~V} \mathrm{~s}^{-1}$ ) against a $\mathrm{Ag} / \mathrm{AgCl}(3 \mathrm{M})$ as reference electrode.

Fig. 3 (a) General XPS spectra for the platinum-modified electrode (Au-SPE/Pt). (b) High-resolution XPS spectra of $\mathrm{Pt} 4 \mathrm{f}_{5 / 2}$ and $\mathrm{Pt} 4 \mathrm{f}_{7 / 2}$ core-level lines.

Fig. 4 (a) Cyclic voltammograms (CV) evolution for a Au-SPE/Pt electrode in a DA solution $\left(10 \mathrm{mM}\right.$ ) for successive voltammetric cycles (scan rate: $20 \mathrm{mV} \mathrm{s}^{-1}$ ). (b) CV of the Au-SPE/Pt and Au-SPE/Pt/PDA electrodes in a solution containing $5 \mathrm{mM}$ $\left[\mathrm{Fe}(\mathrm{CN})_{6}\right]^{3-/ 4-}$.

Fig.5 (a) ATR-FTIR and Raman spectra (b) for Au-SPE/Pt and Au-SPE/Pt/PDA electrodes

Fig. 6 (a) Cyclic voltammograms (CV) of the Au-SPE/Pt/PDA-ChOx electrode in the absence and in the presence of different cholesterol concentrations in $0.1 \mathrm{M} \mathrm{PBST}(\mathrm{pH}$ 7.4) at a scan rate of $0.1 \mathrm{~V} \mathrm{~s}^{-1}$. (b) $\mathrm{CV}$ obtained for a $2.5 \mathrm{mM}$ cholesterol solution at different scan rates (from 0.01 to $0.35 \mathrm{~V} \mathrm{~s}^{-1}$ ) in $0.1 \mathrm{M}$ PBST (pH 7.4). (c) Inset: Linear dependence of the anodic peak against the square root of the scan rate.

Fig. 7 (a) Dependence on temperature of normalized current during the detection of 1 $\mathrm{mM}$ cholesterol (in 0.1 M PBST, pH 7.4) with the Au-SPE/Pt/PDA-ChOx biosensor at 
an applied potential of $0.4 \mathrm{~V}$ and under stirring conditions (400 rpm). (b) Semi-log Arrhenius-type plot obtained for the previous data (Fig. 7a).

Fig. 8 Amperometric responses (a) and calibration curves (b) obtained for cholesterol using the Au-SPE/Pt/PDA-ChOx biosensor in PBST at $400 \mathrm{rpm}\left(\mathrm{E}_{\mathrm{app}}=+0.4 \mathrm{~V}\right)$.

Table 1 Performance comparison of various cholesterol biosensors based on cholesterol oxidase. 
Table 1. Performance comparison of various cholesterol biosensors based on cholesterol oxidase.

\begin{tabular}{|c|c|c|c|c|c|c|}
\hline Biosensor & $\begin{array}{c}\text { Linear range } \\
(\mu \mathrm{M})\end{array}$ & $\begin{array}{l}\text { LOD } \\
(\mu \mathrm{M}) \\
\end{array}$ & $\begin{array}{c}\text { Sensitivity } \\
\left(\mathrm{mA} \mathrm{M}^{-1} \mathrm{~cm}^{-2}\right)\end{array}$ & $\begin{array}{c}\mathrm{K}_{\mathrm{M}} \\
(\mathrm{mM})\end{array}$ & $\begin{array}{l}\text { Stability } \\
\text { (days) }\end{array}$ & Refs. \\
\hline MWCNT-ch-Pt-ChOx & $5-300$ & 4.8 & 44 & - & 7 & [70] \\
\hline ChOx/AuPt-Ch-IL/GCE & $\begin{array}{c}0.05- \\
6.2 \mathrm{mM} \text { and } \\
6.2- \\
11.2 \mathrm{mM}\end{array}$ & 10 & 90.7 & 0.24 & 30 & [69] \\
\hline PEO-co-PPy/ChOx/Pt foil & - & - & 13 & 1.47 & 20 & [73] \\
\hline CP-co-PPy/ChOx/Pt foil & - & - & 11 & 5.16 & 30 & [73] \\
\hline PEDOT/ChOx & - & 400 & 10 & 3.4 & 20 & {$[71]$} \\
\hline Polyaniline -MWCNT/ChOx & $\begin{array}{c}1.26-12.93 \\
\mathrm{mM}\end{array}$ & - & $6.8 \mu \mathrm{A} \mathrm{mM}^{-1}$ & - & 87 & [67] \\
\hline $\mathrm{ZnO} / \mathrm{ChOx}$ & $1-500 \mathrm{nM}$ & 0.37 & 23.7 & 4.7 & 50 & {$[65]$} \\
\hline Pt/PPy-ChOx & up to 300 & 5.7 & 43.99 & 0.59 & - & [72] \\
\hline Pt/poly(3-TPAA)-ChOx & $0-8 \mathrm{mM}$ & 420 & 45 & - & 13 & {$[68]$} \\
\hline Pt/PAn/ChOx & $10-100$ & - & 2.22 & - & - & [40] \\
\hline Au-SPE/Pt/PDA-ChOx & $35.3-500$ & 10.5 & 14.3 & 3.65 & 60 & This work \\
\hline
\end{tabular}




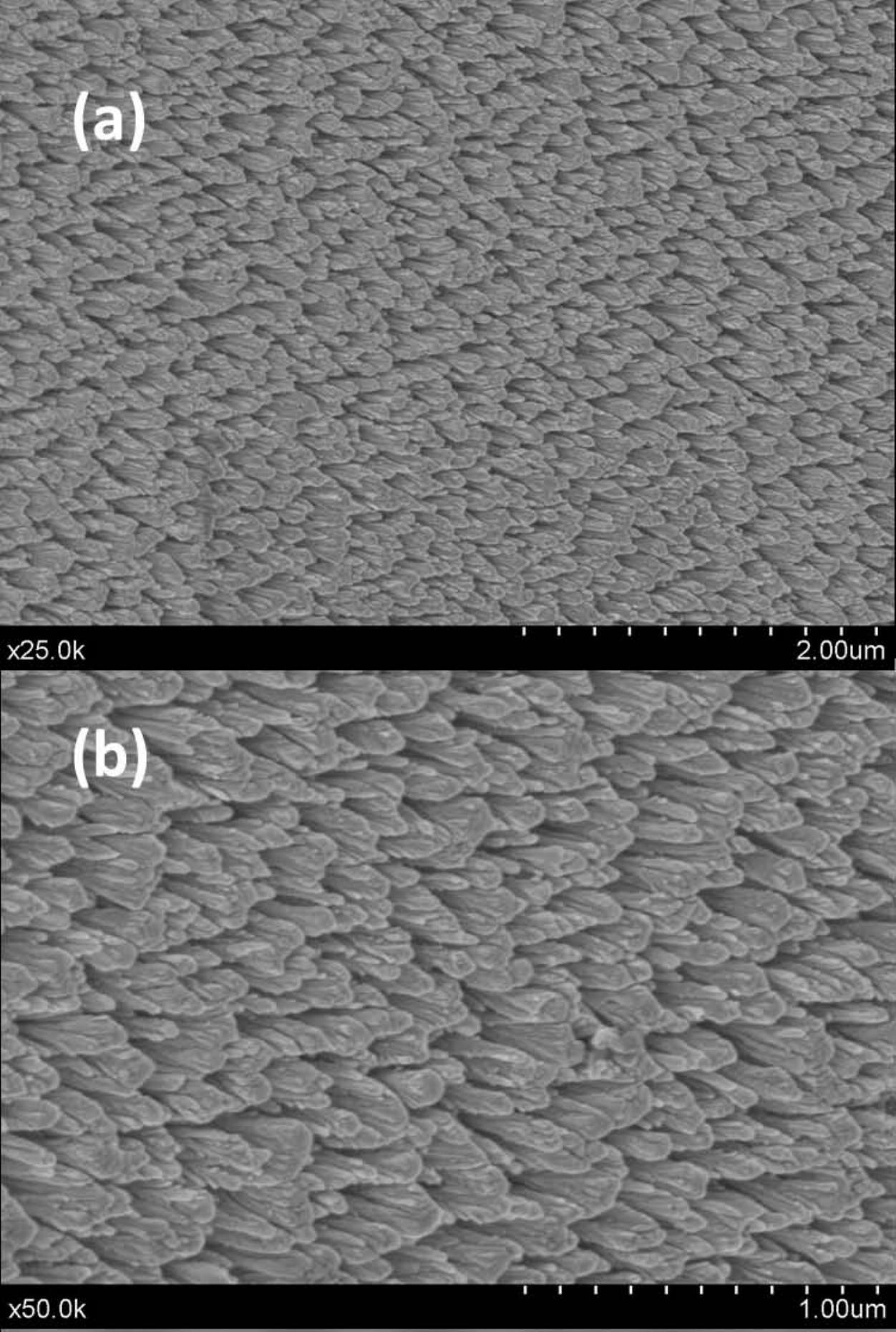



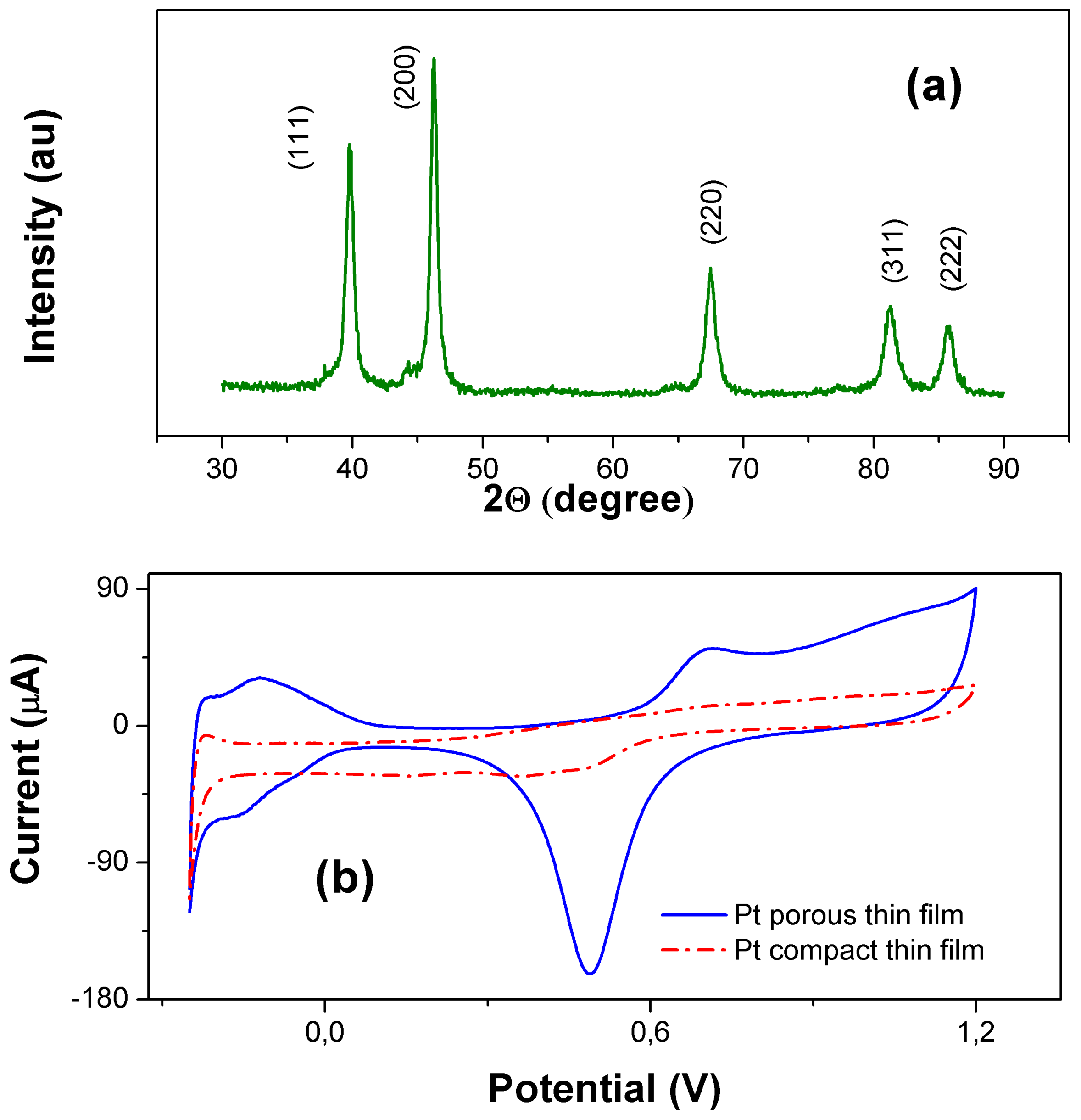

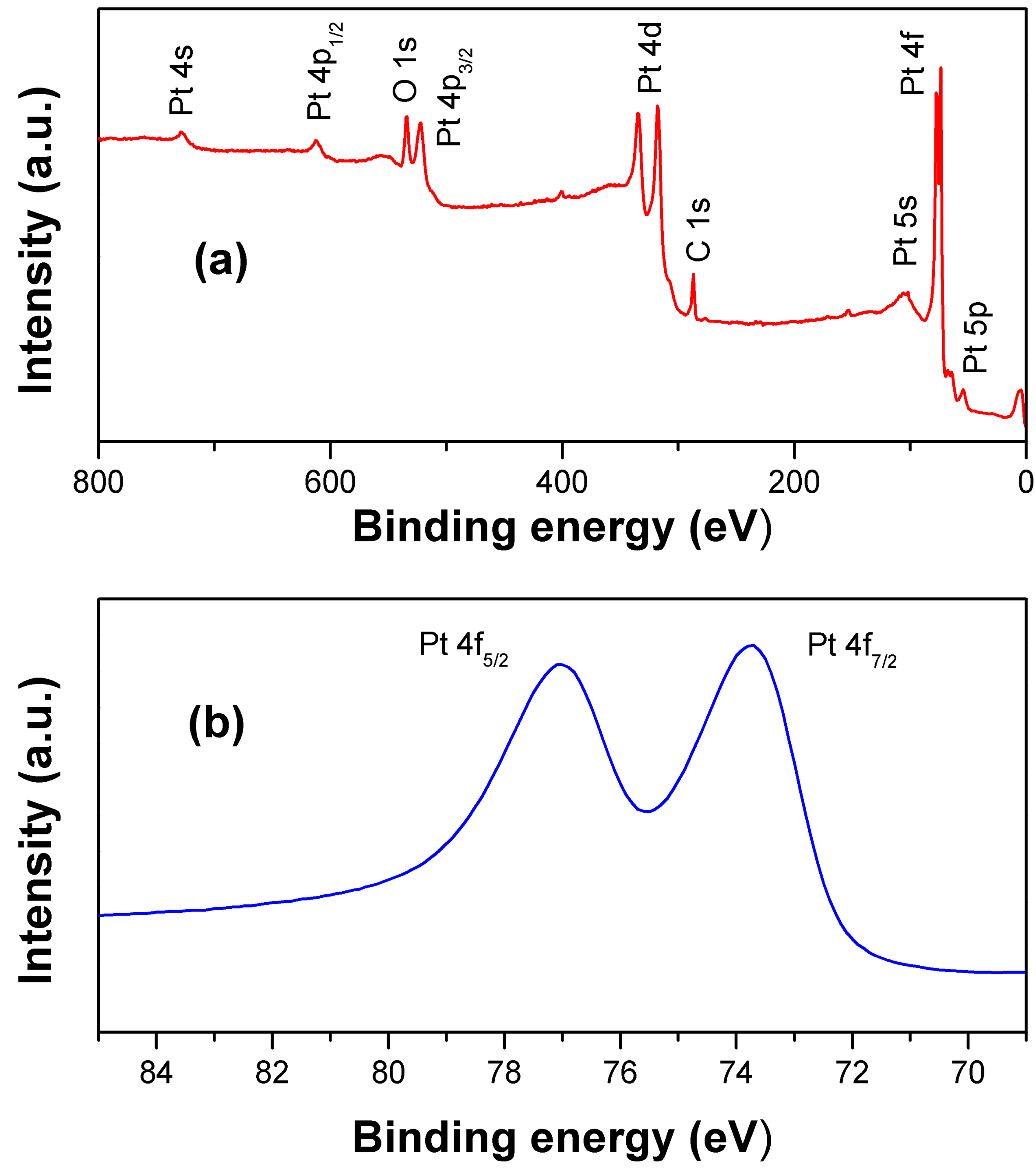

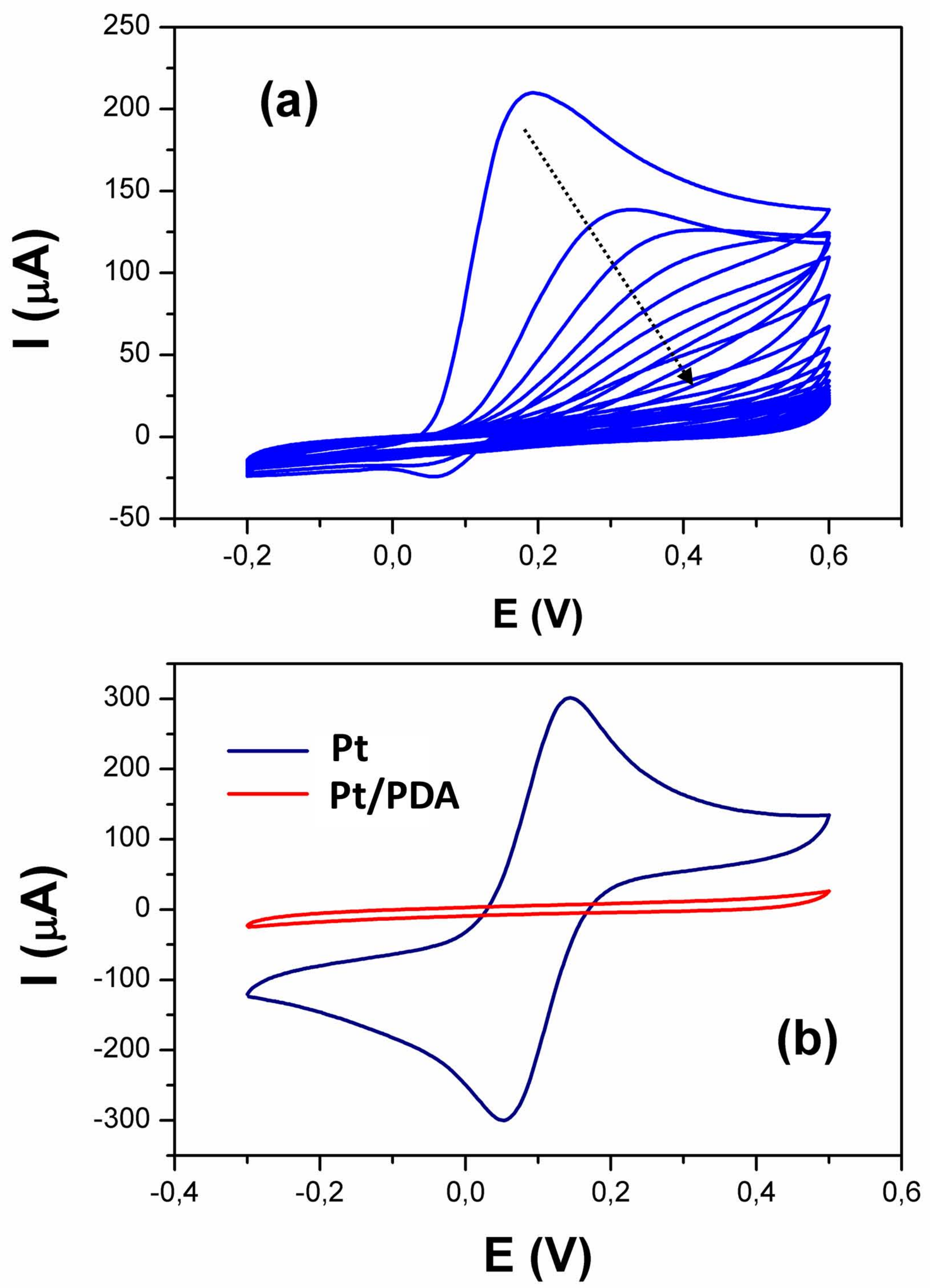
Cholesterol biosensing with a polydopamine-modified nanostructured platinum

electrode prepared by oblique angle physical vacuum deposition

M. Martín ${ }^{1}$, P. Salazar ${ }^{2, *}$, R. Álvarez ${ }^{2}$, A. Palmero², C. López-Santos², J.L. GonzálezMora $^{1}$ and Agustín R. González-Elipe ${ }^{2, \dagger}$

${ }^{1}$ Neurochemistry and Neuroimaging Group, (Laboratory of Sensors, Biosensors and Materials) Faculty of Medical Sciences, University of La Laguna, Campus de Ofra s/n, 38071 La Laguna, Tenerife (Spain)

${ }^{2}$ Laboratory of Nanotechnology on Surfaces, Institute of Materials Science of Seville (CSIC-Univ. Sevilla), Calle Américo Vespucio 49, 41092, Sevilla (Spain)

Corresponding authors: ${ }^{\text {p}}$ salazar@icmse.csic.es, ${ }^{\dagger}$ arge@icmse.csic.es

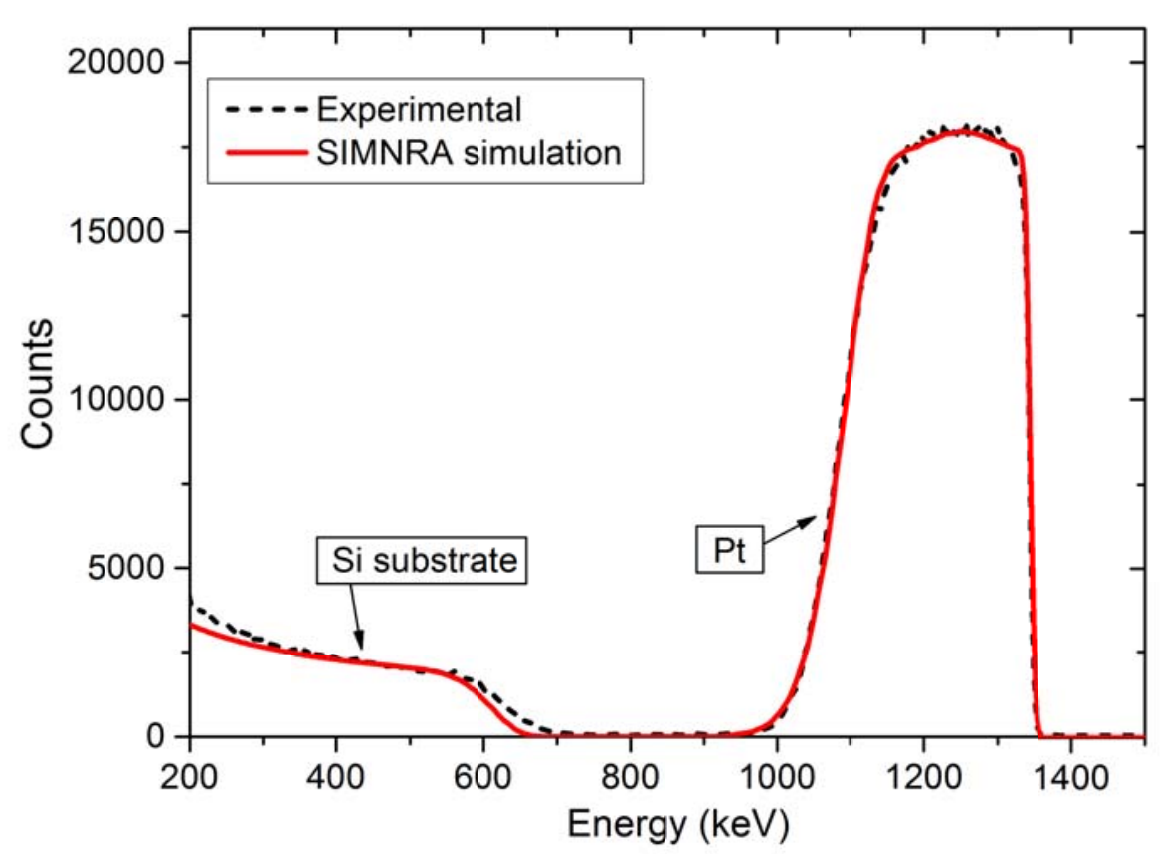

Figure S1. Experimental and simulated RBS spectra with $2.1 \mathrm{MeV}$ alpha particles and $165^{\circ}$ backscatter angle for Pt-modified screen-printed electrode. 


\title{
Cholesterol biosensing with a polydopamine-modified nanostructured platinum
}

electrode prepared by oblique angle physical vacuum deposition

\author{
M. Martín ${ }^{1}$, P. Salazar ${ }^{2, *}$, R. Álvarez ${ }^{2}$, A. Palmero ${ }^{2}$, C. López-Santos², J.L. González- \\ Mora $^{1}$ and Agustín R. González-Elipe ${ }^{2, \dagger}$
}

${ }^{1}$ Neurochemistry and Neuroimaging Group, (Laboratory of Sensors, Biosensors and Materials) Faculty of Medical Sciences, University of La Laguna, Campus de Ofra s/n, 38071 La Laguna, Tenerife (Spain)

${ }^{2}$ Laboratory of Nanotechnology on Surfaces, Institute of Materials Science of Seville (CSIC-Univ. Sevilla), Calle Américo Vespucio 49, 41092, Sevilla (Spain)

Corresponding authors: ${ }^{*}$ psalazar@icmse.csic.es, ${ }^{\dagger}$ arge@icmse.csic.es
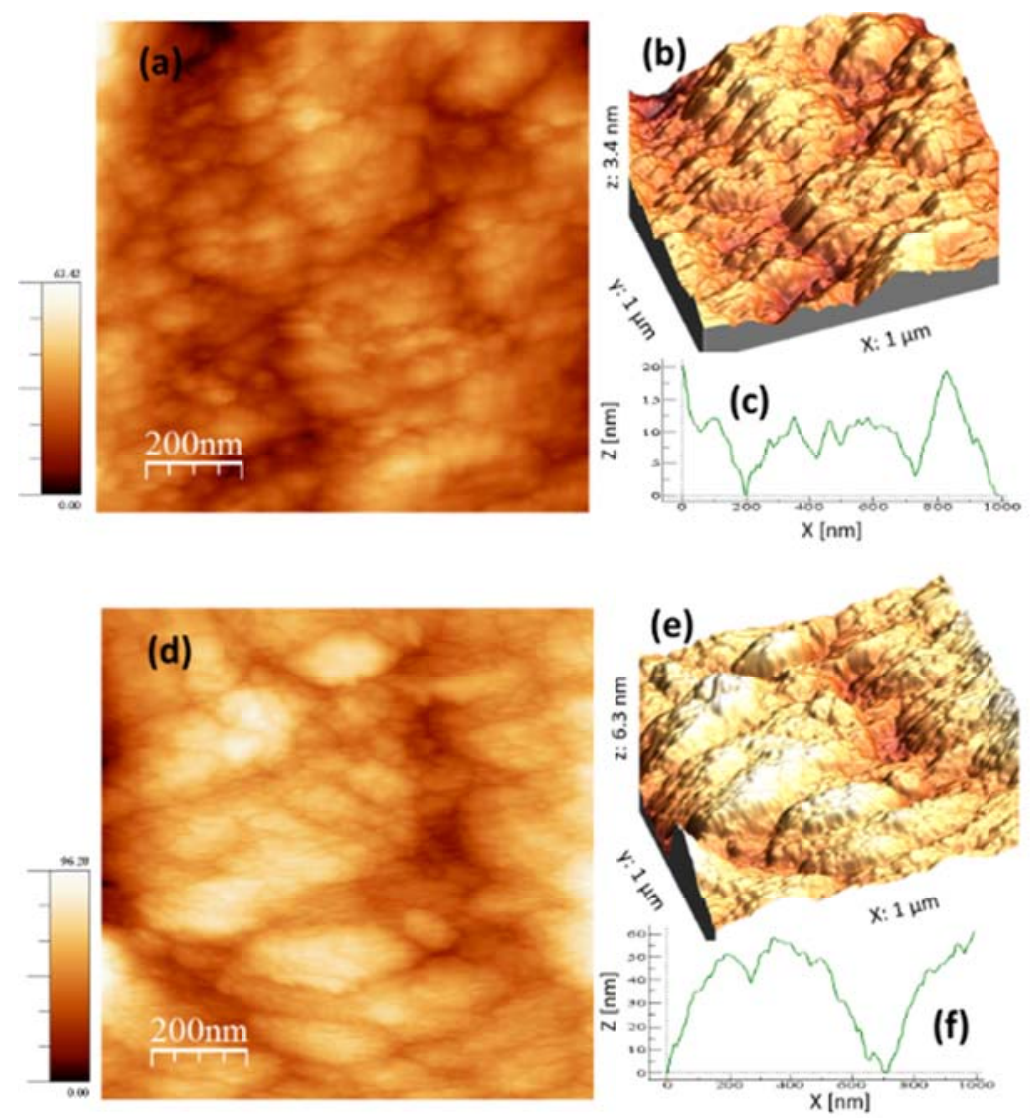

Figure S2. AFM images of the Au-SPE/Pt surface (top) and Au-SPE/Pt/PDA (bottom). 3D plots and average line profiles are included on the right. Contrast scale units: nanometers. 


\section{Cholesterol biosensing with a polydopamine-modified nanostructured platinum}

electrode prepared by oblique angle physical vacuum deposition

M. Martín ${ }^{1}$, P. Salazar ${ }^{2, *}$, R. Álvarez ${ }^{2}$, A. Palmero², C. López-Santos², J.L. GonzálezMora $^{1}$ and Agustín R. González-Elipe ${ }^{2, \dagger}$

${ }^{1}$ Neurochemistry and Neuroimaging Group, (Laboratory of Sensors, Biosensors and Materials) Faculty of Medical Sciences, University of La Laguna, Campus de Ofra s/n, 38071 La Laguna, Tenerife (Spain)

${ }^{2}$ Laboratory of Nanotechnology on Surfaces, Institute of Materials Science of Seville (CSIC-Univ. Sevilla), Calle Américo Vespucio 49, 41092, Sevilla (Spain)

Corresponding authors: ${ }^{\text {p}}$ salazar@icmse.csic.es, ${ }^{\dagger}$ arge@icmse.csic.es

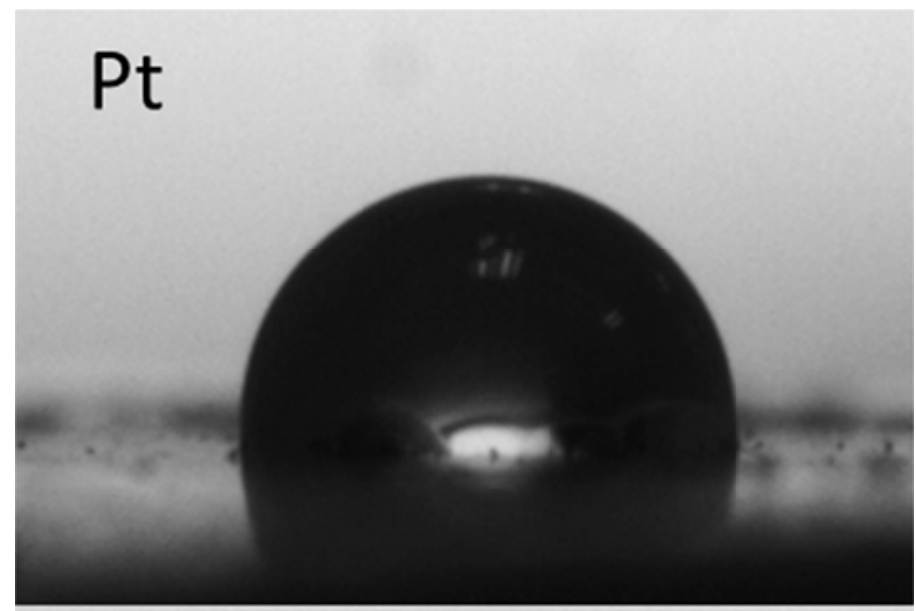

\section{$\mathrm{Pt} / \mathrm{pDA}$}

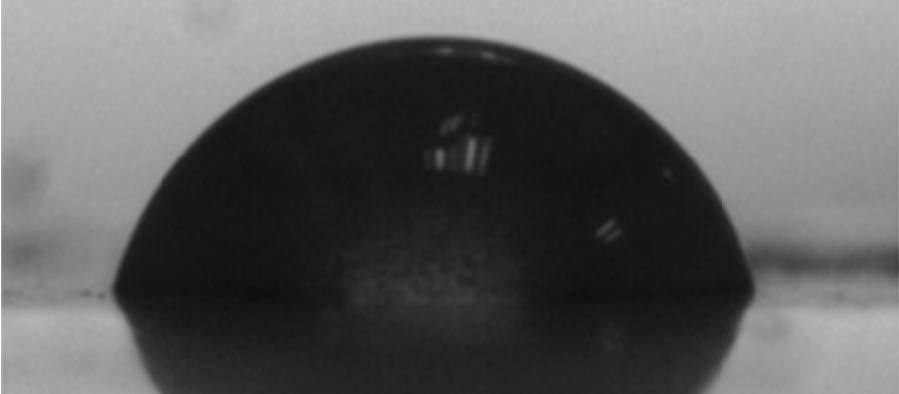

Figure S3. Photographs of a 3ul water droplet for Au-SPE/Pt (a) Au-SPE/Pt/PDA (b) electrodes. 


\section{Cholesterol biosensing with a polydopamine-modified nanostructured platinum}

electrode prepared by oblique angle physical vacuum deposition

M. Martín ${ }^{1}$, P. Salazar ${ }^{2, *}$, R. Álvarez², A. Palmero², C. López-Santos², J.L. GonzálezMora $^{1}$ and Agustín R. González-Elipe ${ }^{2, \dagger}$

\footnotetext{
${ }^{1}$ Neurochemistry and Neuroimaging Group, (Laboratory of Sensors, Biosensors and Materials) Faculty of Medical Sciences, University of La Laguna, Campus de Ofra s/n, 38071 La Laguna, Tenerife (Spain)

${ }^{2}$ Laboratory of Nanotechnology on Surfaces, Institute of Materials Science of Seville (CSIC-Univ. Sevilla), Calle Américo Vespucio 49, 41092, Sevilla (Spain)

Corresponding authors: ${ }^{*}$ psalazar@icmse.csic.es, ${ }^{\dagger}$ arge@icmse.csic.es
}

Chronoamperometry was used to study the biosensor response under static conditions. This first study, together with CV data, helped us to confirm the good biosensor response against cholesterol. However, a detailed study in order to optimize the main experimental variables, is showed below (FigSXXXXX). Figure S4 shows the plots current vs. time for the Au-SPE/Pt/ChOx bisensor recorded by stepping the applied potential from open circuit conditions to $0.7 \mathrm{~V}$ against the Ag pseudoreference electrode, in the absence and in the presence of cholesterol in a range varying from 0 to $10 \mathrm{mM}$ in PBST solution. Data showed a linear dependence at low cholesterol
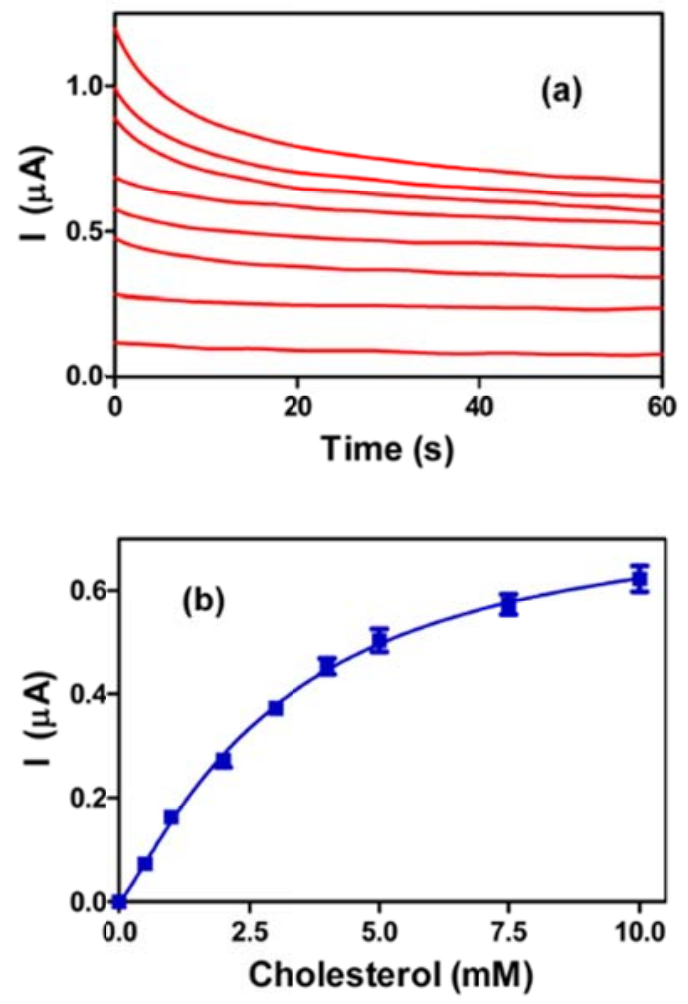
concentrations and a saturated response at high concentrations, in agreement with the Michaelis-Menten kinetics (see manuscript).

Figure S4. (a) Chronoamperogram for our cholesterol biosensor obtained in PBST form 0 to $10 \mathrm{mM}$ cholesterol at applied potential of $0.7 \quad \mathrm{~V} \quad$ vs internal Ag-pseudoreference electrode. (b) Calibration curve for the biosensor in (a). 


\section{Cholesterol biosensing with a polydopamine-modified nanostructured platinum}

electrode prepared by oblique angle physical vacuum deposition
M. Martín ${ }^{1}$, P. Salazar ${ }^{2, *}, \mathrm{R}$
R. Álvarez ${ }^{2}$, A. Palmero ${ }^{2}$,
C. López-Santos², J.L. González-

Mora $^{1}$ and Agustín R. González-Elipe ${ }^{2, \dagger}$

${ }^{1}$ Neurochemistry and Neuroimaging Group, (Laboratory of Sensors, Biosensors and Materials) Faculty of Medical Sciences, University of La Laguna, Campus de Ofra s/n, 38071 La Laguna, Tenerife (Spain)

${ }^{2}$ Laboratory of Nanotechnology on Surfaces, Institute of Materials Science of Seville (CSIC-Univ. Sevilla), Calle Américo Vespucio 49, 41092, Sevilla (Spain)

Corresponding authors: ${ }^{*}$ psalazar@icmse.csic.es, ${ }^{\dagger}$ arge@icmse.csic.es
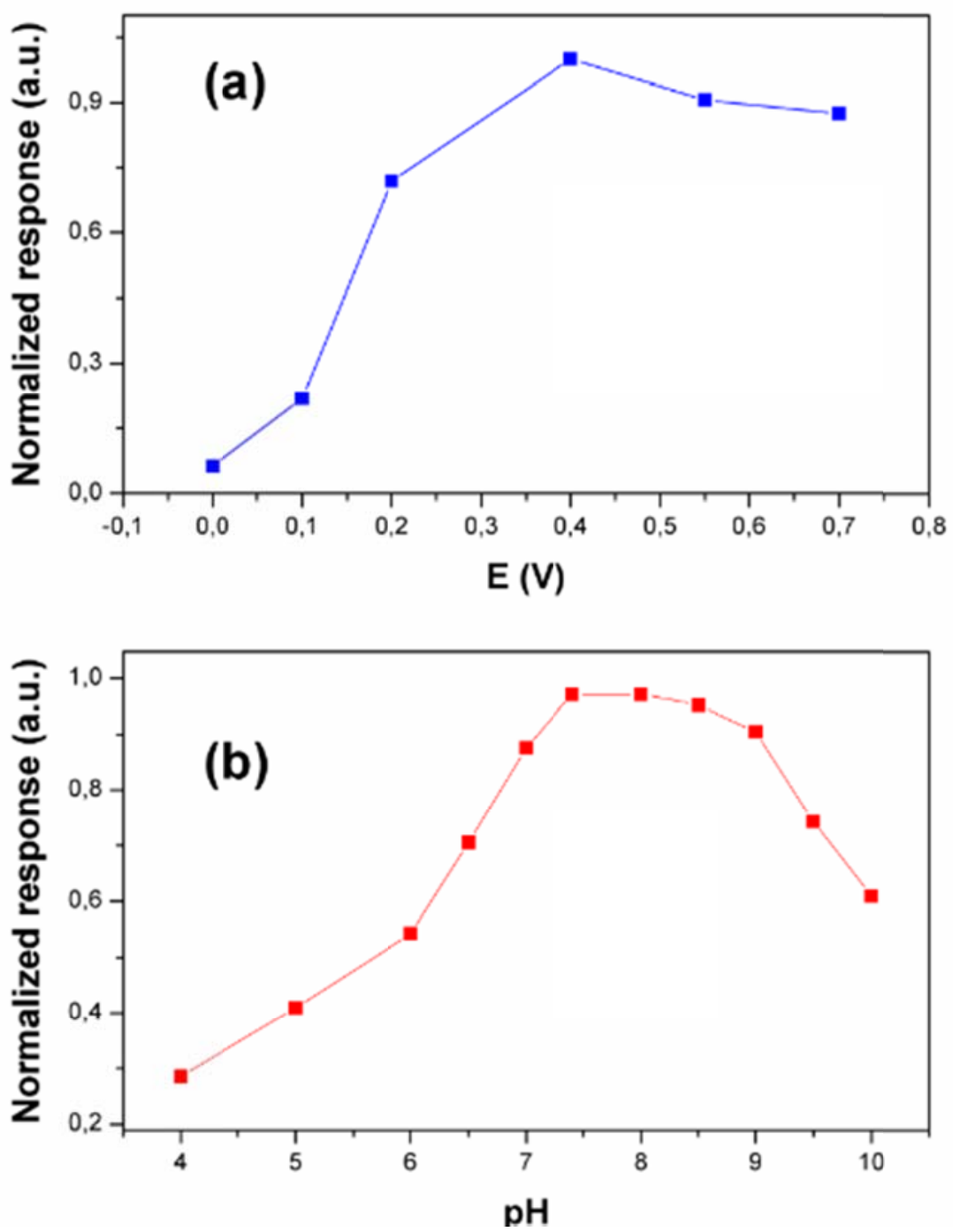

Figure S5. Optimization of different experimental variables for our cholesterol

bioensor: (a) applied potential; (b) pH of the buffer solution. 


\section{Cholesterol biosensing with a polydopamine-modified nanostructured platinum}

electrode prepared by oblique angle physical vacuum deposition

M. Martín ${ }^{1}$ P. Salazar,* ${ }^{2,}$ R. Álvarez², A. Palmero², C. López-Santos², J.L. GonzálezMora $^{1}$ and Agustín R. González-Elipe ${ }^{2, \dagger}$

${ }^{1}$ Neurochemistry and Neuroimaging Group, (Laboratory of Sensors, Biosensors and Materials) Faculty of Medical Sciences, University of La Laguna, Campus de Ofra s/n, 38071 La Laguna, Tenerife (Spain)

${ }^{2}$ Laboratory of Nanotechnology on Surfaces, Institute of Materials Science of Seville (CSIC-Univ. Sevilla), Calle Américo Vespucio 49, 41092, Sevilla (Spain)

Corresponding authors: ${ }^{\text {p}}$ salazar@icmse.csic.es, ${ }^{\dagger}$ arge@icmse.csic.es

Table S1. Determination of cholesterol concentrations in different prepared samples

\begin{tabular}{ccccc}
\hline $\begin{array}{c}\text { Cholesterol } \\
\text { mM }\end{array}$ & $\begin{array}{c}\text { Au-SPE/Pt/PDA- } \\
\text { ChOx biosensor }\end{array}$ & $\begin{array}{c}\text { Recovery } \\
\text { (\%) }\end{array}$ & $\begin{array}{c}\text { Spectrophotometric } \\
\text { Method }\end{array}$ & $\begin{array}{c}\text { Recovery } \\
\text { (\%) }\end{array}$ \\
\hline $\mathbf{2 . 5}$ & 2.41 & 96.30 & 2.44 & 97.75 \\
$\mathbf{5}$ & 5.05 & 100.93 & 5.15 & 102.90 \\
$\mathbf{7 . 5}$ & 7.41 & 98.77 & 7.64 & 101.91 \\
$\mathbf{1 0}$ & 10.29 & 102.86 & 10.16 & 101.59 \\
\hline
\end{tabular}
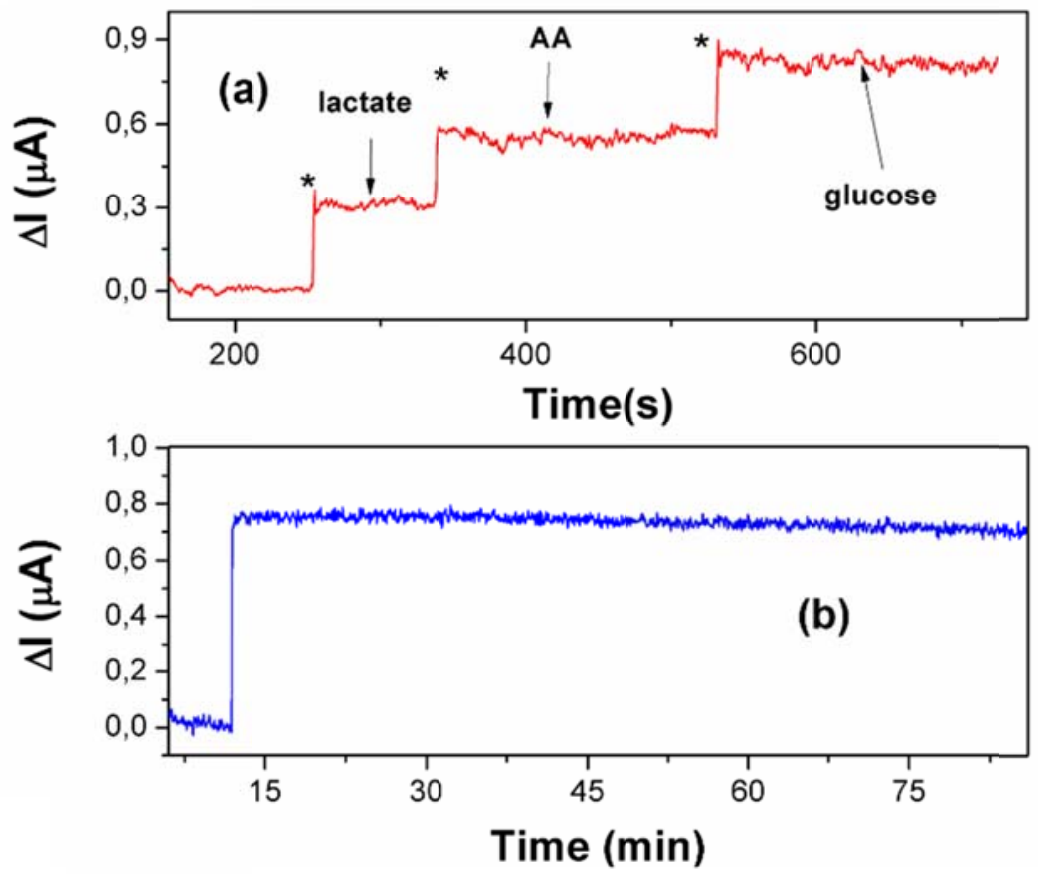

Figure S6 (a) Amperometric response of the cholesterol biosensor for $300 \mu \mathrm{l}$ of $5 \mathrm{mM}$ cholesterol additions (*) in $10 \mathrm{~mL}$ of PBST against similar additions of interferences: $0.1 \mathrm{mM}$ AA and 5mM glucose and lactate. (b) Biosensor stability during ca. $1 \mathrm{~h}$ after adding $400 \mu \mathrm{M}$ of cholesterol. 
Cholesterol biosensing with a polydopamine-modified nanostructured platinum

electrode prepared by oblique angle physical vacuum deposition

M. Martín ${ }^{1}$, P. Salazar ${ }^{2, *}$, R. Álvarez ${ }^{2}$, A. Palmero², C. López-Santos², J.L. GonzálezMora $^{1}$ and Agustín R. González-Elipe ${ }^{2, \dagger}$

${ }^{1}$ Neurochemistry and Neuroimaging Group, (Laboratory of Sensors, Biosensors and Materials) Faculty of Medical Sciences, University of La Laguna, Campus de Ofra s/n, 38071 La Laguna, Tenerife (Spain)

${ }^{2}$ Laboratory of Nanotechnology on Surfaces, Institute of Materials Science of Seville (CSIC-Univ. Sevilla), Calle Américo Vespucio 49, 41092, Sevilla (Spain)

Corresponding authors: ${ }^{\text {p}}$ salazar@icmse.csic.es, ${ }^{\dagger}$ arge@icmse.csic.es

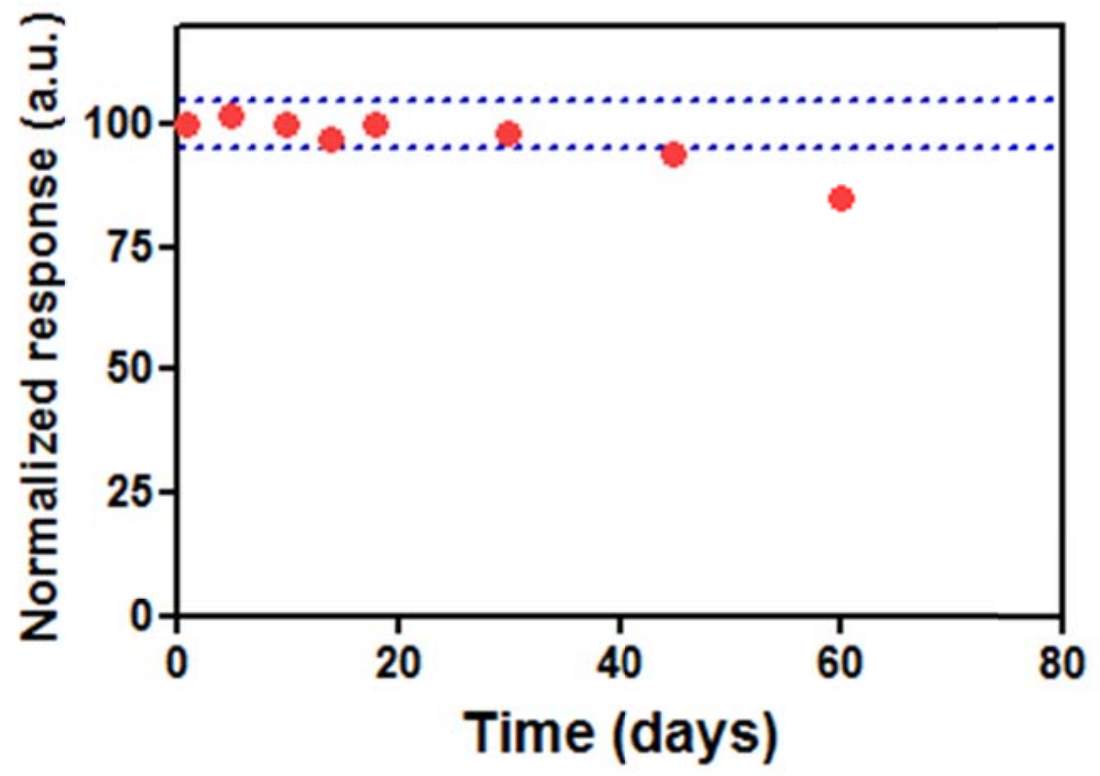

Figure S7 Storage stability of our cholesterol biosensor stored at $4{ }^{\circ} \mathrm{C}$ during a period of 2 months. Each value represents the mean value of three different measurements. The upper and lower control limits (dashed lines) were set at \pm 3 SD of the initial value. 